\title{
Account
}

\section{Recent Progress in Luminescent Lanthanide Complexes for Advanced Photonics Applications}

\author{
Hwan Kyu Kim," Jae Buem Oh, Nam Seob Baek, Soo-Gyun Roh, Min-Kook Nah, and Yong Hee Kim \\ Center for Smart Ligh-Harvesting Materials and Deparment of Polymer Science \& Engineering. \\ Hamam University; Daejeon 306-79l, Korea. "E-mail: hwankkim@mail.hamam.ac.kr.
}

Received October 19. 20104

\begin{abstract}
We have designed and developed novel luminescent lanthanide complexes for advanced photonics applications. Lanthanide(III) ions $\left(\mathrm{Ln}^{3+}\right)$ were encapsulated by the luminescent ligands such as metalloporphyrins and naphthalenes. The energy levels of the luminescent ligands were tailored to maintain the effective energy transfer process from luminescent ligands to $\mathrm{Ln}^{3-}$ ions for getting a higher optical amplification gain. Also, key parameters for emission enhancenent and efficient energy transfer pathways for the sensitization of $\mathrm{Ln}^{3+}$ ions by luminescent ligands were investigated. Furthermore, to enhance the optophysical properties of novel luminescent $\mathrm{Ln}^{3+}$ complexes, aryl ether-functionalized dendrons as photon antennas have been incorporated into luminescent $\mathrm{Ln}^{3+}$ complexes, yielding novel $\mathrm{Ln}(\mathrm{III})$-cored dendriner complex. The novel Ln(III)-cored dendrimer complex has nuch higher PL intensity than the corresponding simple complex, due to the efficient site-isolation effect. In this article, we will deal with recent progress in the synthesis and photophysical studies of inert and stable luninescent $\mathrm{Ln}^{3+}$ complexes for advanced photonics applications. Also, our review will include the exploratory investigation of the key paraneters for emission enhancement and the effective energy transfer pathways from luminescent ligands to $\mathrm{Ln}^{3+}$ ions with $\mathrm{Ln}(\mathrm{III})$ chelated prototype complexes.
\end{abstract}

Key Words : Luminescent lanthanide complexes, Lanthauide-cored dendrimer complexes, Near infrared emission, Energy transfer pathways, Advanced photorics applications

\section{Introduction}

Very recently, the development of integrated planar waveguide optical amplifiers is extremely essential for the realization of superhigh speed communication systems of large capacity optical communication, information storage, and processing. ${ }^{.}$At present, erbium-doped silica amplifiers are widely used. But, the poor solubility of lanthanide cations ( $\left.\mathrm{Ln}^{3-}\right)$ in conventional inorganic/organic media leads to low amplification property. When the higher doping
Hwan Kyn Kim was born at Ulsan (Korea) in 1958 . He recejved B.S. in applied chemistry from Lniversity of Ulsan (1980), M.S. in chemistry from KAIST (1982) and $\mathrm{Ph}$. D in polymer chemistry from Canegie Mellon University (1990) where he studied after research experience at KRICT (1982-1986). After postdoctoral research in Materials Science and Engineering at Cornell University (1991-1993), he joined ETRI (1993-1994). He moved to Hannam Lniversity where he is currently a Professor of Polymer Science and Engineering. Since 2001, he is a leader of Center for Smart Light-harvesting Materials supported from Korea Ministy of Science and Teclunology.

Soo-Gyun Roh (b. 1960) grew up in Gyeongsangbuk-do, Korea. He studied chemistry at Daegu Lniversity (B.S., 1987), Kyungpook National Lniversity (M.S., 1989) and Lniversité de Piene et Marie Curie (Paris 6 University, Ph.D., 1994). After research at Kyungpook National Lniversity, KAIST and POSTECH, he joined Center for Simart Light-harvesting Materials at Hannam Liniversity since 2002. Currently, he works as a research professor at Hannam University:

Yong Hee Kim (b. 1965) yrew up in Deajeon, Korea. She recejved a B.S. (1987), a M.S (1989), and a Ph.D. (1992) in chemisty from Chungnam National Lniversity (1992). After postdoctoral research at KRISS during 4 years, she joined the company for development of science education program where she was a senior researcher. She joined the Center for Smart Light-harvesting Materials as a research professor at Hannam University (2003).
Nam Seob Baek was bon in Mungyeong, Korea, in 1974. He received his B.S. and Master`s degree in Department of Polymer Science and Engineering from Hannam University (2002) and he joined the Center for Smart Light-Harvesting Materials at Hanuam Lniversity. He is currently completing his Pl.D. work in Materials Science and Engineering under direction of Professor Hwan Kyu Kim at Hannam Lniversity. His research interests lie in the field of advanced photonics materials based on supramolecular and organometallic chemistry.

Min-Kook Nah (b. 1974) received a B. Sc. in chemistry from Woosuk University (1998). He received a M. S. in chemistry from Chungnam National University (2000). He joined the Center for Smart Light-Harvesting Materials at Hannam University. He is currently completing his Ph.D. work in Physical Chemistry at Chungnam National University. His research interests lie in the field of molecular spectroscopy.

Jae Buem Oh (b. 1975) grew up in Daejeon, Korea. He received a B.S. (1999) and a Master's degree in chemistry from Hannam University (2001). After research experience at KRICT within l year, he joined the Center for Smart Light-Harvesting Materials at Hannam University. He is currently completing his Ph.D. work in Materials Science and Engineering under direction of Professor Hwan Kyu Kim at Hamlam Lniversity. His research interests lie in the field of advanced photonics materials based on supramolecular and organometallic chemistry. 
concentration of $\mathrm{Ln}^{3-}$ was introduced, clustered $\mathrm{Ln}^{3+}$ species can be formed, which in turn have limited amplification property. It is ascribed to the cooperative energy-transfer processes (i.e., self-quenching process) between the clustered $\mathrm{Ln}^{3+}$ species. Their processes reduced the intensity of luminescence. Because of this reason, it is impossible to obtain high efficiency of optical anplification by doping $\mathrm{Er}^{3+}$ ions in silica optical fiber. Also it is difficult to expect optical amplification of $30 \mathrm{~dB}$ in planar waveguide form, since the amplified luminescence intensity in $\mathrm{Ln}^{3+}$ ions by direct excitation is very low due to their low absorption and emission cross sections.

In order to enhance the amplified luminescence intensity, luminescent ligands are being used to excite the $\mathrm{Ln}^{3-}$ ions via an energy transfer from the luminescent ligands to the $\mathrm{Ln}^{3-}$ ions. The development of luminescent $\mathrm{Ln}^{3+}$ complexes based on the energy transfer mechanisms by using the supramolecular complexes as organic ligands has been extensively studied and attracted considerable attention because of their academic interest and potential utility in a wide variety of applications, such as planar waveguide amplifiers, plastic lasers, and light-emitting diodes. ${ }^{2-19}$ In most cases, luminescent $\mathrm{Ln}^{3+}$ complexes consist of a $\mathrm{Ln}^{3+}$ ion and a chelating luminescent ligand which acts as a sensitizer that transfers excitation energy to the encapsulated $\mathrm{Ln}^{3-}$ ion; the presence of this kind of ligand overcomes the lanthanide ion's intrinsically low luminescence intensity by direct excitation of the $\mathrm{Ln}^{3+}$ ion having low absorption and emission cross-sections. Luminescent ligands efticiently absorb and transfer energy to the central $\mathrm{Ln}^{3-}$ ions. The

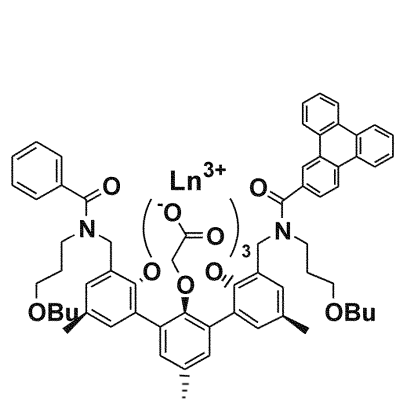

Ln(terph-triph)

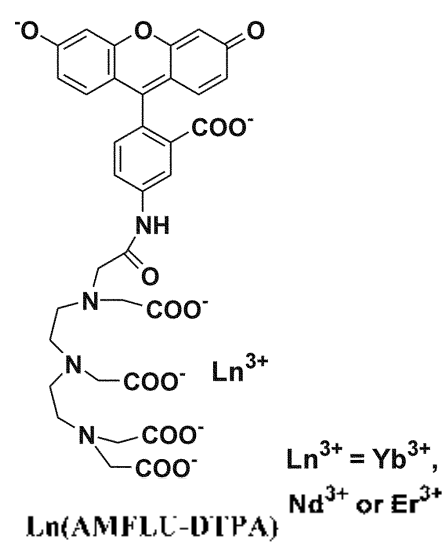

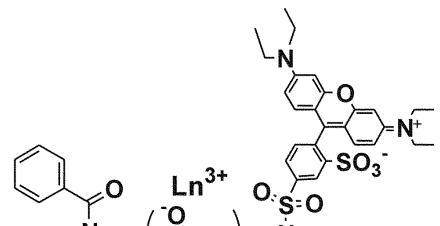

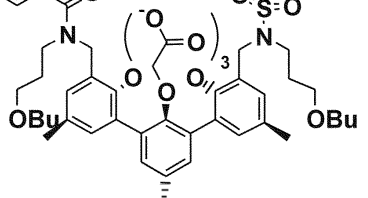

I.n(terph-lissam)

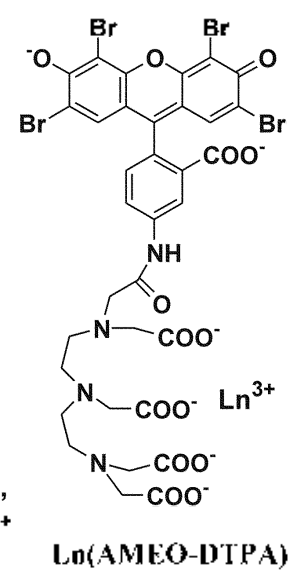

central $\mathrm{Ln}^{3+}$ ions accumulate energy from the antenna chromophores, producing a strong and narrow bandwidth emission.

For examples. Reinhoudt $e t a l$. synthesized polydentate hemispherand complexes containing triphenylene ${ }^{5.6}$ or lissamine group. ${ }^{7.8}$ where triphenylene and lissamine act as antenna chromophores. The $\mathrm{Ln}^{3-}$ complexes showed the near infrared (IR) emissions by the indirect excitation of antenna chromophores. The $\mathrm{Ln}^{3-}$ complexes show a relatively high intersystem crossing (ISC) quantum efficiency such that $\mathrm{Ln}^{3+}$ ions are easily excited by the triplet state of chromophores. They found that the near IR emission takes place through the energy transfer process between the triplet state of chromophores and a $\mathrm{Ln}^{3-}$ ion.

Werts $e t a l^{\text {" }}$ synthesized luminescent $\mathrm{Er}^{3-}$ complexes such as AMFLU-DTPA and AMEO-DTPA based on fluorescein and tetra-bromoeosin and they observed near IR luminescence. They reported that the effective ISC efficiency was required for getting the stronger emission bands.

Gillan and Curry ${ }^{10-12}$ synthesized a series of $\operatorname{Er}($ III $)$-cored complexes based on tris(8-hydroxyquinoline) for the use of the applications such as optical amplification (OA) materials and light-emitting devices (LED). They observed near IR luminescence and electroluminescence at $1.54 \mu \mathrm{m}$ in the multilayered light-emitting devices (LED). Also, Yanagita et al. ${ }^{13-15}$ synthesized $\mathrm{Ln}^{3+}$ complexes using tris(dibenzoylmethanato) ligand and observed near IR electroluminescence from organic LEDs by utilizing them.
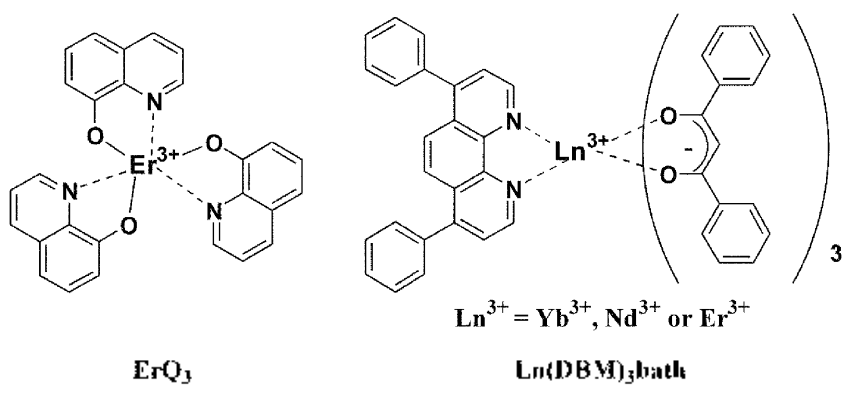

Harrison et $a{ }^{1 / 6}$ synthesized an Er(TPP)acac complex by using porphyrin as a ligand, and demonstrated the possibility of light-emitting material by doping in PPV series polymer materials. Recently, Schanze et al. studied the fabrication of near IR polymer LED using blending a series of lanthanide tetraphenylporphyrin (LnTPP) complexes in non-conjugated host polymers. ${ }^{17}$ Recently, Destri $e t a l .{ }^{18}$ synthesized Er(III)cored complexes based on oligothiophene derivatives and observed near IR luminescence via energy transfer process, taking place between $\mathrm{Er}^{3-}$ ion and oligothiophene derivative.

Recently, Kawa and Fréchet have also reported the site isolation and antenna effects on luminescent properties of spherical Ln(III)-cored dendrimer complexes. ${ }^{19}$ The poor solubility of $\mathrm{Ln}^{3-}$ cations in inorganic media leads to clustered $\mathrm{Ln}^{3+}$ species, limiting the amplification achievable. To achicve the site isolation of $\mathrm{Ln}^{3+}$ cations such as $\mathrm{Eu}^{3+}$, $\mathrm{Tb}^{3-}$ or $\mathrm{Er}^{3+}$ ions, lanthanide ions were surrounded by the dendritic shell such as aryl-ether type dendrons. They found 


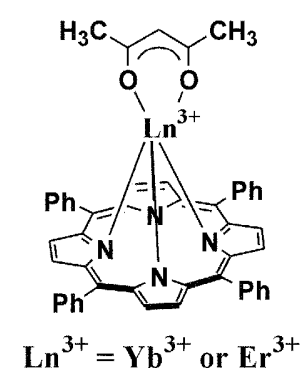

Ln(TPP)acac

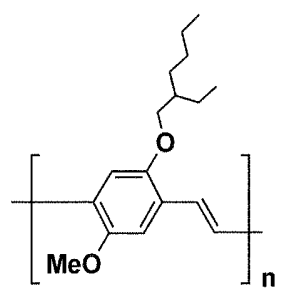

VEH-PPV

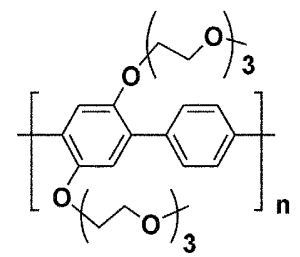

PPP-ORII

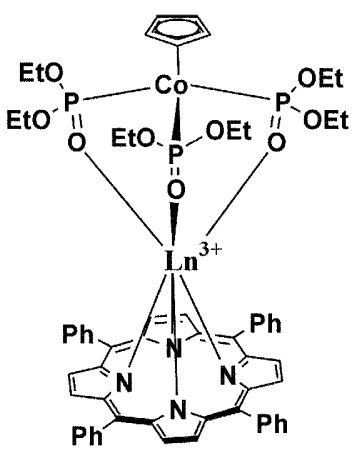

$\operatorname{Ln}(T P P) L(O E t)$

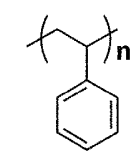

polystyrene

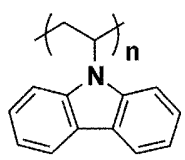

PVK that the enhanced luminescent intensities depend significantly on the morphology of the dendrimer and efficient energy transfer from the photonic antennas to rare earth ion at the rocal point. However, $\operatorname{Er}($ III)-cored dendrimer complexes did not exhibit near IR emission. Although the aryl-ether type dendrons were widely used to photonic antennas. its spectral overlap between the emission band of photonic antenna and the absorption band of $\mathrm{L} \mathrm{n}^{3-}$ cation was not satisfied to obtain the effective energy transfer between the photonic antenna and the $\mathrm{Ln}^{3-}$ cation.

Up to dale, luminescent $\mathrm{Ln}^{3-}$ complexes containing supramolecular ligands as antenna chromophores were not developed for the real use in various photonics applications, such as crbium-doped fiber amplifiers (FDF/), crbiumdoped waveguide amplifiers (Г.T)W diodes. They are simply supramolecular complexes containing well-known antenna chromophores to photocxite the I. $n^{3-}$ ions via the energy transfer process. The quantum yield of energy transfer and the luminescence efliciency were not satisfied yet. $\Lambda$ lso, such elforts are just in the early stage and not only the basic concept not established, but also the structure-property relationship is not yet clearly understood. Therefore, the dependence of $\mathrm{Ln}^{3-}$ ion and ligand structure on amplification principles (such as the optical amplitication lifetime, excited state dynamics, etc.) need to be systematically established. Based on the relationship established, the design and synthesis of lumineseent $\left[n^{3-}\right.$ complexes using molecular engineering approach need to be investigated.

Therefore, recently, we have systematically designed and developed In(III)-cored complexes based on metalloporphyrins and naphthalenes, in a novel synthetic method developed in our laboratory, for advanced photonics applicalions. ${ }^{210-22} \mathrm{LnI}^{3-}$ ions were encapsulated by the lumineseent ligands such as metalloporphyrins and naphthalenes. Also, key parameters for emission enhancement and efficient encrgy transfer pathways for the sensitization of ${\mathrm{I} . \mathrm{n}^{3-}}^{3-}$ ions by luminescent ligands were investigaled. ${ }^{22}$ We found that the saturated 8- or 9-coordinated complexes have the much stronger PI. intensily than the unsaturaled 6-coordinated complex. Very recently, we have incorporated a G2-arylether functionalized dendron into the Er(III)-cored complex, yielding novel $\operatorname{Cr}(\mathrm{III})$-cored dendrimer complex bearing the Pl(II)-porphyrin. The Er(III)-cored dendrimer complex shows the stronger near IR emission intensity than the corresponding complex based on Pl(II)-porphyrin by 7 times in solid slate.

In this article, we will deal with recent progress in the synthesis and photophysical studies of inert and stable luminescent $\mathrm{Ln}^{3-}$ complexes for advanced photonics applications. Also, our review will include the exploratory investigation of the key parancters for emission cnhancement and the effective energy transfer pathways from Juminescent ligands to $\mathrm{Ln}^{3-}$ ions with $\mathrm{Ln}(\mathrm{III})$-chelated protolype complexes.

\section{Lanthanide Ions and Basic Optical Amplification Principle of Lanthanide Ions}

The electronic configurations of $\mathrm{Ln}^{3-}$ ions, referred to as the lanthanide ions or rare earth ions, have $4 f^{\prime \prime}(n-1-14)$ structures, which fill the $4 f$ orbital according to the atomic numbers starting from $\mathrm{Ce}^{3-}$ to $\mathrm{Lu}^{3-}$ ions. These ions all have an incompletely lilled $f$ subshell in which the $f$-electrons are shiclded by the outer $5 s$ and $5 p$ electrons, which are lower in energy, but spatially located outside the $4 f$ orbitals. These electrons are slightly perturbed by the effects of lattice phonons and static strain ficlds in the coordination environment of ions, lead to the sharp spectral lines. Since the spin-orbit interaction is larger than the effect of the crystal ficld, the lumineseence spectra consist of groups of lines which arise from crystal field splittings of $J$ multiplets of the free ion in general. ${ }^{23.24}$

Judd ${ }^{25}$ and Ole $\mathrm{et}^{26}$ independently derived expressions for the oscillator strength of induced dipole transitions within the $4 f^{n}-4 f^{n}$ configuration. Since their results are similar and were published simultancously, their results are known as the Judd-Ofelt theory. They summed over the intensities of the individual crystal field components of a given state. The fundamental mechanism of the Judd-Ofelt theory is the perturbation caused by mixing of the crystal field potentials between the orbitals with different parities and $4 f^{\prime \prime}$ orbitals. The $4 f^{\prime \prime}-4 f^{\prime \prime}$ transitions are lorbidden because $4 f^{\prime \prime}$ of rare earth ions and energy levels of electron shells have equal parity. However, absorption spectra between $4 f^{\prime \prime}-4 f^{n}$ transition are experimentally observed. This is explained by assuming that a higher-lying opposite parity contiguration is 
mixed into the $4 f^{n}$ states via the potential due to the ligand field..$^{27}$ On the contrary, $4 f^{n-} 4 f^{n-1} 5 d^{1}$ transitions or charge transfer transitions $\left(4 f^{\prime \prime}-4 f^{n-1} 5 L^{1}, \mathrm{~L}-\right.$ ligand) are partly allowed by mixing with the odd-parity wave functions via the potential due to the crystal field. The absorption and emission cross-sections are very small in solid phase and the corresponding fluorescence decay times are sufficiently long (as of the order of $m$ ), compared with the rate at which it is populated in the excitation process. Also there is a Stark splitting between the degenerated $4 f$ energy levels by the effect of electric field near $\mathrm{Ln}^{31}$ ions removing the degeneracy of the $4 f$ level.

In analyzing the mechanisms of excited state relaxation of lanthanides in crystal hosts, two modes of relaxation are recognized: radiative and radiationless (or non-radiative) processes. $\mathrm{Axe}^{28}$ represented the radiative processes in quantitative terms using the Judd-Ofelt theory. Radiationless relaxation was formulated in terms of multiphonon relaxation processes. ${ }^{.99 .30}$ Such processes become less probable as the energy gap between an excited state and the next lower cnergy state increases. Since excited state relaxation is generally achieved prior to transitions to several lower-lying states, a total radiative relaxation rate can be defined as a summation over all states lower in energy than the fluorescing state. Scheme 1 shows the principal fluorescence states of the $\mathrm{Ln}^{31}$ ions in crystal hosts. ${ }^{31}$ Fluorescence from many of these levels is observed only at low temperatures since rapid relaxation of an excited state by radiationless processes compete strongly with the radiative mode unless the energy gap to the next lower level is large. As the gap increases, the process rapidly decreases in probability such that radiative decay can efficiently compete with a relaxation mechanism. Usually both radiative and radiationless processes operate to relax an excited state. The total fluorescence lifetime of the state is a sum of the radiative rate and the rates of the various radiationless processes.

Several lanthanide ions, such as $\mathrm{Pr}^{3}, \mathrm{Nd}^{3}, \mathrm{Dy}^{3}, \mathrm{Er}^{3}$, and $\mathrm{Yb}^{3}$ ions, show luminescence in the near infrared region. The luminescence of wavelengths $1.54 \mu \mathrm{m}$ from $\mathrm{Fr}^{3}$ ion and $1.34 \mu \mathrm{m}$ from $\mathrm{Nd}^{3}$ ion is used as standard wavelengths in optical communications, in which light is used to transport information between different users. Some of lanthanide ions, such as $\mathrm{Sm}^{31}, \mathrm{~Tb}^{3}$ and $\mathrm{Eu}^{3}$ ions, exhibit the emission band in the visible region. Their luminescent complexes have been considered the potential candidates for light-emitting diodes.

Among them, erbiun-based materials have attracted much attention because they have the authentic optical amplification (OA) property with the strong stimulated emission band. This specific property renders erbium-based materials to use in several photonics applications, such as crbiumdoped fiber amplifiers (EDFA), erbium-doped waveguide amplifiers (EDWA) and light-emitting diodes. ${ }^{1.21}$ The basic optical amplification principle of $\mathrm{Fr}^{3}$ ion is described in

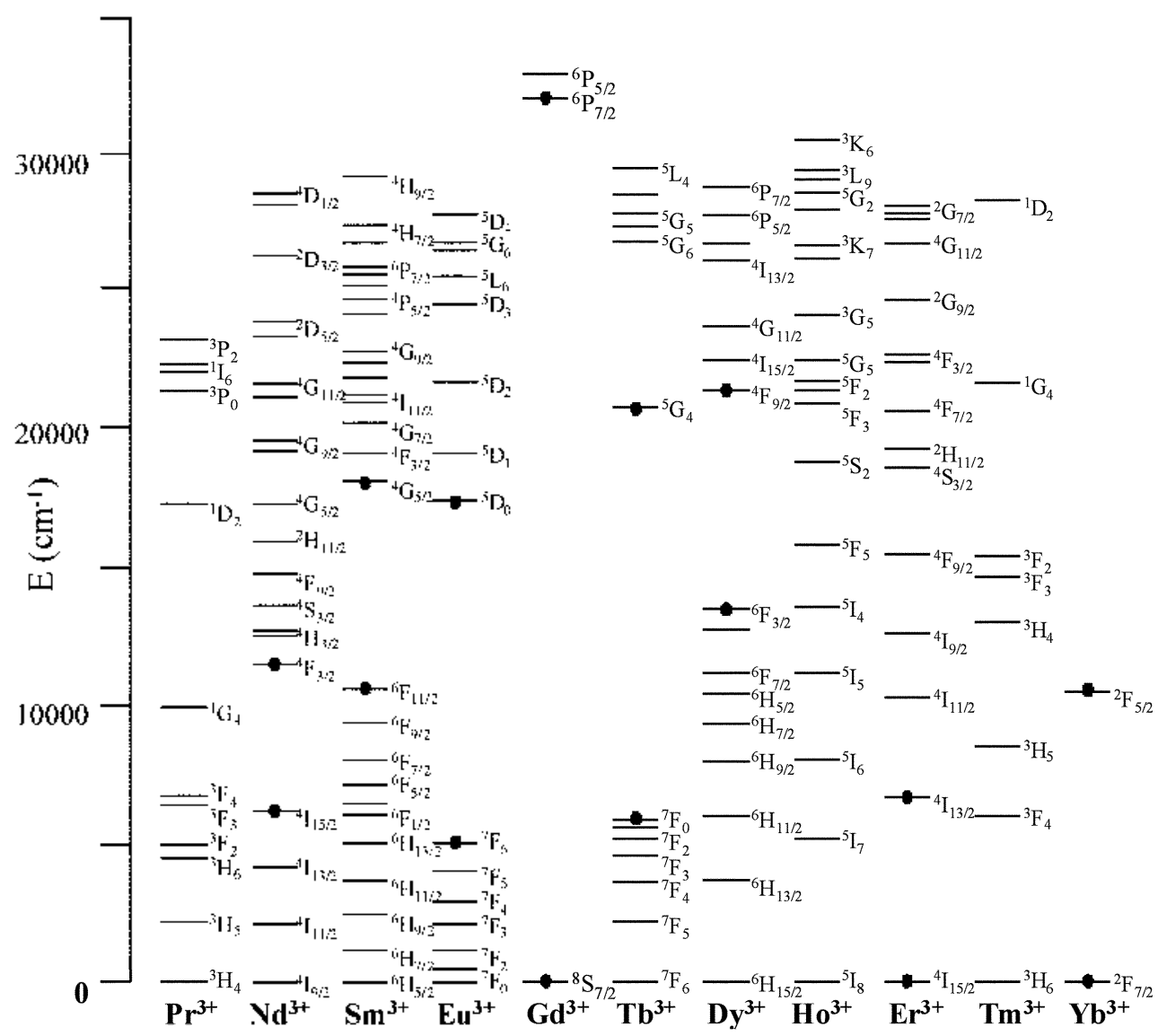

Scheme 1. Energy levels of $\mathrm{Ln}^{3-}$ ions. 

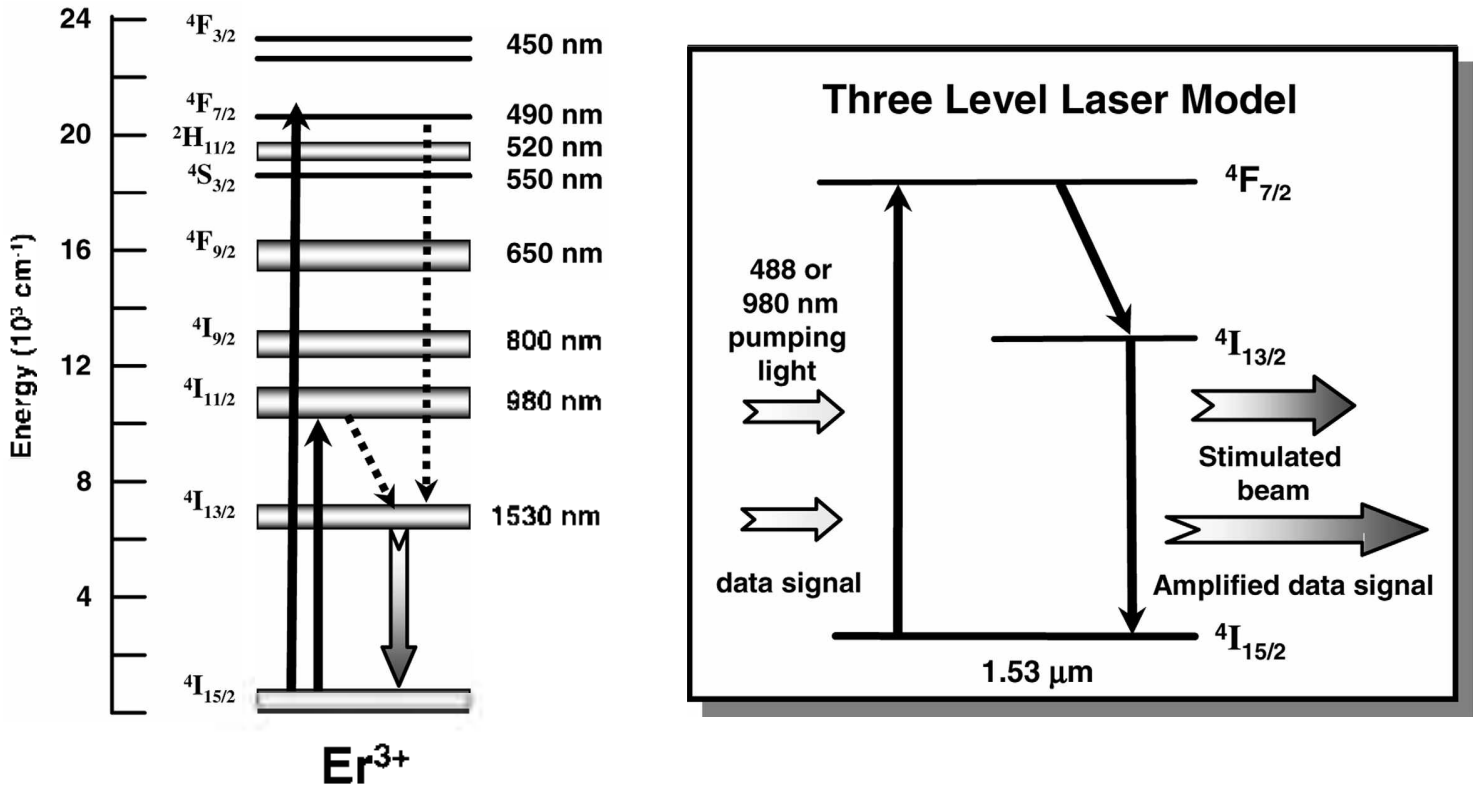

Scheme 2. Basic optical amplitication principle of $\mathrm{Er}^{3 \cdot}$ ions for advanced photonics applications.

Scheme 2. The Er ${ }^{i-}$ ion is excited to the upper energy level than the lower excited energy level $\left(\mathrm{Er}^{3-},{ }^{4} \mathrm{I}_{13_{2}}\right)$ of the lanthanide ions, by absorbing photons of pumping laser such as 488 or $980 \mathrm{~nm}$, etc. And then, the excited state of the upper energy level is transited to the lower excited energy Ievel $\left(\mathrm{T}_{\mathrm{r}} \mathrm{r}^{3-},{ }^{4} \mathrm{I}_{1,32}\right)$ of the $\mathrm{I}_{\mathrm{n}} \mathrm{n}^{3-}$ ions through the lattice relaxation process (or the vibrational relaxation process). The population inversion inherently takes place at the energy Ievel of the lanthanide ions $\left(\mathrm{Cr}^{3-},{ }^{4} \mathrm{I}_{1,2}\right)$. Finally, it loses the photon energy in a radiative decay to fall back to the ground state $\left(\mathrm{Er}^{3-},{ }^{4} \mathrm{~J}_{14 \cdot 2}\right)$ of the $\mathrm{Ln}^{3-}$ ions, emitting the stimulated light at $1.54 \mathrm{fm}$. When the same inpul signal with the melastable excited state is introduced at the same time, the input signal and the stimulated emission beam are summed to generate the amplified output signal, due to the power interchange between the input signal and the stimulated emission beam. The stimulated emission lifetime of the ${ }^{4} I_{13: 2}$ $\rightarrow{ }^{+} /_{15: 2}$ radiative transition at $1.54 / \mathrm{mm}$ of $\mathrm{Er}^{3-}$ ion in a solid, which depends on the presence of impurities and defects in the host, is of the order of $10 \mathrm{~ms}$. In luminescent $\mathrm{Ln}^{3-}$ complexes, instead of direct excitation of $\Gamma \mathrm{r}^{3-}$ ion in a solid, the luminescent ligands, as photon sensitizers, efliciently absorb and transfer the light to excite the $\mathrm{Ln}^{3-}$ ions via an energy transfer between the lumineseent ligand and the $I_{.} \mathrm{n}^{3-}$ ion. It is very important to note that the accumulating photon energy from the excited state of the luminescent ligands can excite the $\mathrm{Ln}^{3-}$ ions as much as possible, thus enhancing the optical amplification gain.

\section{Er(III)-chelated Prototype Complexes: Exploratory Synthesis and Key Parameters for Near IR Emission Enhancement}

For the first of all, we altempled to synthesize Cr(IJI)chelated complexes using $\operatorname{Er}(\mathrm{III})$ acetate, according to the previous Frechet's method. ${ }^{14}$ But, the reaction did not take<smiles>[X]c1c([X])c([X])c(C(=O)O)c([X])c1[X]</smiles>

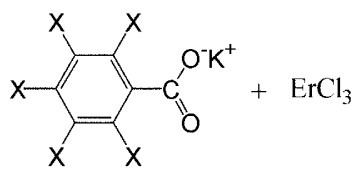<smiles>[X]c1c([X])c(C(C)C)c([X])c(C(O)C(C)C)c1[X]</smiles>

$\operatorname{Er}(H-b e n z))_{3}(x=H) ; \operatorname{Er}(F-b e n z)_{3}(x=F)$

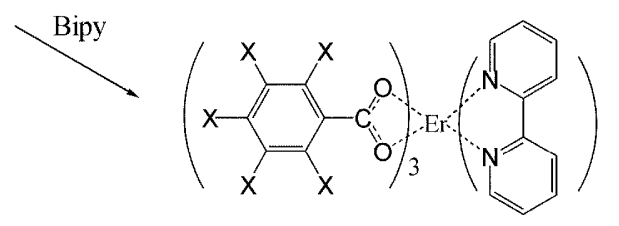

$\operatorname{Er}(H-b e n z)_{3}($ bipy $)(x=H) ; \operatorname{Er}(F-b e n z)_{3}($ bipy $)(x=F)$

Scheme 3. New synthetic route to Er(lli)-chelated complexes based on benzoate and pentafluorobenzoate ligands and their chemical structures. 


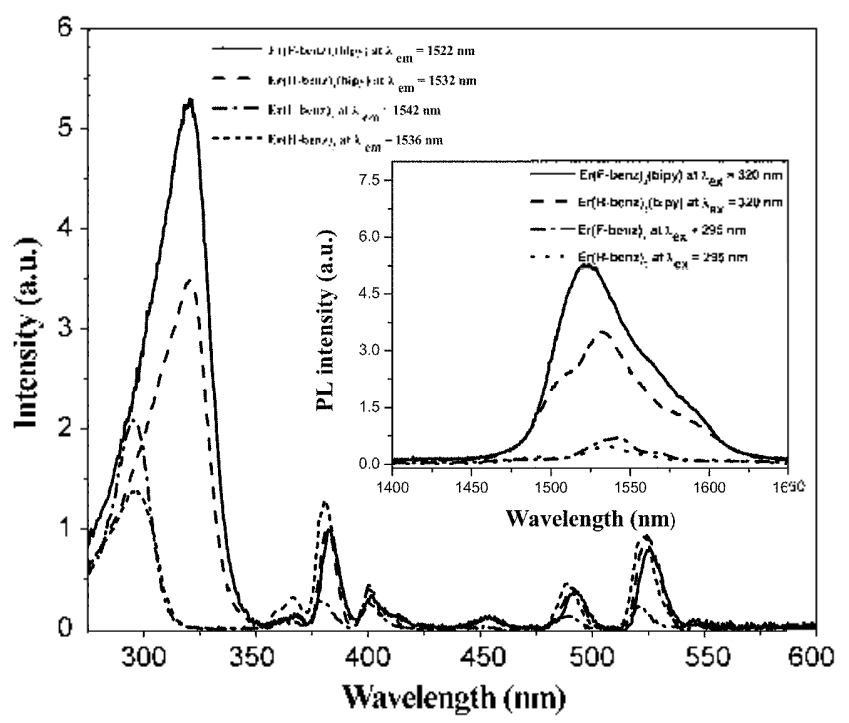

Figure 1. Excitation spectra of the 6- or 8-coordinated model

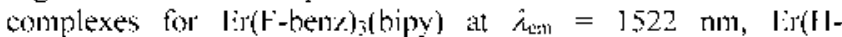
benz); (bipy) at $\lambda_{n-1}=1532 \mathrm{~nm}, \operatorname{Er}(\Gamma-b e n z)_{3}$ at $\lambda_{\mathrm{m}}=1542 \mathrm{~nm}$, and Er(H-benz) $)_{3}$ at $\lambda_{\mathrm{m}}=1536 \mathrm{~nm}$ in a solid state. Here, the $\lambda_{\mathrm{m}}$ means the emission wavelength. The inset shows near IR spectra of $\mathrm{Er}(\mathrm{F}-$ benz) $)_{3}\left(\right.$ bipy) at $\lambda_{\mathrm{v}}=320 \mathrm{~nm}$, Er(II-benz) (bipy) at $\lambda_{\mathrm{w}}=320 \mathrm{nnm}$, Eir(f-benz $)_{3}$ at $\lambda_{\mathrm{w}}=295 \mathrm{~nm}$, and I:r(II-benz.) $)_{3}$ at $\lambda_{\mathrm{w}}=295 \mathrm{~nm}$ in solid state. Here, the $\lambda_{\mathrm{s}}$ means the excitation wavelength.

place because of the side reactions. ${ }^{20}$ Very recently, we have developed a new synthetic method for 6- and 8-coordinated Fr(III)-cored model complexes through the ligand-cxchange reaction using $\mathrm{ErCl}_{3}$ (see Scheme 3$)^{22} \Lambda$ first. the salts of benzoate or pentaflurobenzoate were prepared from the reaction of the organic ligands with $\mathrm{KH}$ in dry $\mathrm{THF}$ and then the corresponding salts of the ligands reacted with ErCl. The successlul synthesis of $\operatorname{Tr}(\mathrm{III})$-chelated protolype complexes was proved by elementary analysis, thermal gravimetric analysis (TG $\Lambda$ ), FT-IR, absorption and emission spectroscopies. But, the paramagnetic properties of $\mathrm{Er}^{3-}$ complexes do not permit NMR characterization of the model complex. From TG $\Lambda$ analysis, at least three $\mathrm{H}_{2} \mathrm{O}$ molecules coordinated in the unsaturated 6-coordinated complexes were confirmed by determining the relcasing water amount of $6 \%$ up to $190^{\circ} \mathrm{C}$ in atmospheric condition. However, 8coordinated model complexes $\operatorname{Er}(\mathrm{H}-$ benz $)$ (bipy) and $\operatorname{Er}(\mathrm{F}$ benz) (bipy) showed no releasing waler up to 170 " $\mathrm{C}$. indicating that 8-coordinated model complexes contain no coordinated $\mathrm{H}_{2} \mathrm{O}$ molecules.

The absorption spectra of 8-coordinated prototype complexes of $\operatorname{Er}(\mathrm{H} \text {-benz })_{3}$ (bipy) and $\operatorname{Er}(\mathrm{F} \text {-benz) })_{3}$ (bipy) show a very intense absorption band at $310 \mathrm{~nm}$, which is attributed to $\pi-\pi^{*}$ electronic transition. The emission spectra of all compexes at the selected photoexcitation wavelength exhibit the emission bands in the near IR region of 1.47-1.63 $\mathrm{fm}$, which are assigned to the characteristic ${ }^{4} \mathrm{I}_{1,22} \rightarrow{ }^{4} \mathrm{I}_{152}$. transition of $\mathrm{Er}^{-{ }^{-}}$ions. Figure 1 shows the the emissoin spectra of the 6- and 8-coordinated complexes at the photocxcitation wavelenglh of 295 or $320 \mathrm{~mm}$ (sec the insed). The saturated 8-coordinated complexes show much stronger

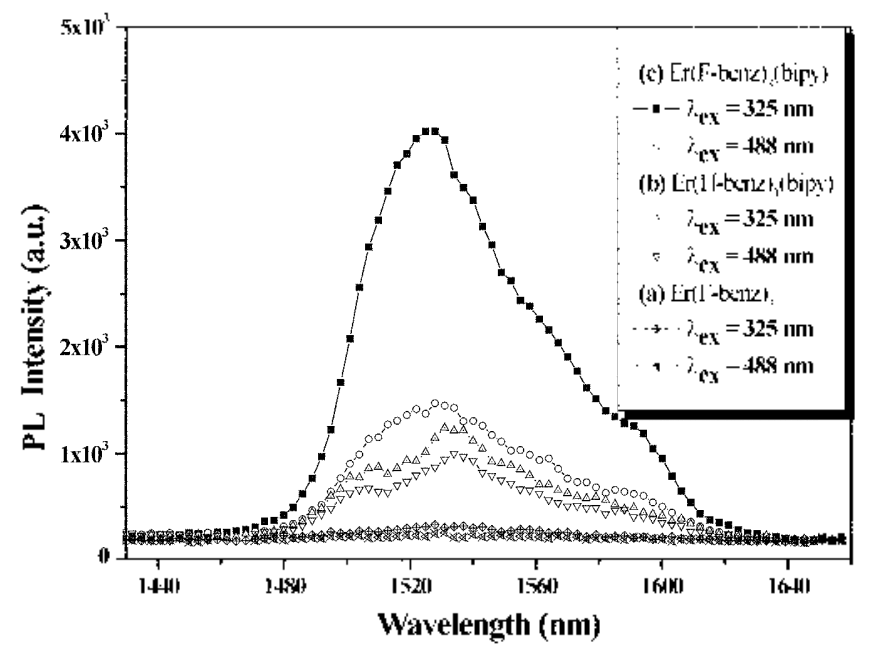

Figure 2. Near IR emission spectra of the 6- or 8-coordinated model complexes for (a) Er(F-benz) 3 , (b) Er(H-benz) (bipy), and (c) Er(F-benz) s(bipy) in a solid state.

PL intensity than that of the unsaturated 6-coordinated complex. The similar result has been shown in a previous report. ${ }^{21}$ The excitation spectra of the 8-coordinated prototype complexes of $\operatorname{Er}(\mathrm{H} \text {-benz })_{3}$ (bipy) and $\operatorname{Er}\left(\mathrm{F}-\text { benz }_{3}\right)_{3}$ (bipy), monitored at the maximum emission band, show a strong maximum band at $335 \mathrm{~nm}$ in the utraviolet region, whereas the excitation spectra of the 6-coordinated complexes of $\Gamma \mathrm{r}(\mathrm{H} \text {-ben } /)_{\text {. }}$ and $\Gamma \mathrm{r}(\mathrm{F} \text {-ben })_{3}$ exhibit the bands at $295 \mathrm{~nm}$. $\Lambda$ so, the scveral additional excitation bands appeared in the region of $350-550 \mathrm{~nm}$. These excited bands spectrally overlap well with the absorption bands of the inherent $\Gamma \mathrm{r}^{3-}$ ion. ${ }^{1.21}$ Thus, the energy transfer between the excited organic ligand and the ground $\mathrm{Er}^{3-}$ ion takes place.

Figure 2 shows the near IR emission bands of the 6coordinated and 8-coordinated prototype complexes, corresponding to the characteristic ${ }^{4} \mathrm{I}_{13: 2} \rightarrow{ }^{4} \mathrm{I}_{\mathrm{s}-2}$ transition of $\mathrm{Er}^{3-}$ ions taking place at $1.53 \mathrm{~km}$, upon a photoexcitation wavelength of 325 or $488 \mathrm{~mm}$. Here, upon the photoexcitation wavelength of $325 \mathrm{~mm}$, the energy transfer process between the excited ligand and $\mathrm{Er}^{3-}$ ion takes place possibly to gencrate the emission of the central $\mathrm{I}^{3-}{ }^{3-}$ ion ( $\mathrm{Fr}^{3-}$ ion), while, upon the photoexcitation wavelength of $488 \mathrm{~nm}$, the emission of the inherent $\mathrm{Ln}^{3-}$ ion $\left(\mathrm{Er}^{3-}\right.$ ion) was obtained through the direct excitation of $\mathrm{Fr}^{3-}$ ion without the energy transfer process between the excited ligand and $\mathrm{Er}^{3-}$ ion. The saturated 8-coordinated complexes show much stronger PL intensity than that of the unsaturated 6-coordinated complex as shown in Figure 1 \& 2, in which the highly coordinated Ln(III)-chelated complexes (at least 8 to 9 coordination) have the higher PI. elliciency than the unsaturated I.n(IJI)chelated complexes ( 6 coordination). ${ }^{21}$ In the latter complex, at least three $\mathrm{H}_{2} \mathrm{O}$ molecules coordinated in the unsaturated 6-coordinated complexes scriously quenched the noar IR emission by the hamonic vibration relaxation decay of $\mathrm{O}-\mathrm{H}$ bonds in these $\mathrm{H}_{2} \mathrm{O}$ molecules. It reduces greatly the intensity of the near IR cmission. Nlso, the saturated 8coordinated complexes, oblained with a photoexcitation 
wavelength at $325 \mathrm{~nm}$, exhibit much higher PL intensity than that obtained from the direct photoexcitation of $\mathrm{Er}^{3-}$ ions with $488 \mathrm{~nm}$ by 80 times

Furthermore, we have investigated the influence of $\mathrm{C}-\mathrm{F}$ bonds on near IR emission by comparing the PL intensity of a 8-coordinated model complex with $\mathrm{C}-\mathrm{F}$ bonds ( $\mathrm{Er}(\mathrm{F}$ benz) s(bipy)) with that of a 8 -coordinated model complex with $\mathrm{C}-\mathrm{H}$ bonds $(\operatorname{Er}(\mathrm{H}-$ benz) (bipy)). The PL intensity at the near IR emission is proportional to the density of excited ions in the upper energy level $\left({ }^{4} I_{13}\right)$. The higher the excited ion density increases, the stronger the PL intensity at the near IR emission obtains. Therefore, it is necessary to enhance the excited ion density in upper energy level for getting the stronger near IR emission intensity. The excited ion density in the upper energy level $\left({ }^{4} \mathrm{I}_{132}\right)$ strongly depends on the multi-phonon relaxation process. The multi-phonon relaxation process is one of the nonradiative transitions, where the photon energy is absorbed by the harmonic vibration motion to convert to the thermal energy, instead of light emission. Figure 2 shows that $\operatorname{Er}(F-b e n z)$ (bipy) has much stronger $\mathrm{PL}$ intensity than that of $\operatorname{Er}(\mathrm{H}-\text { benz) })_{3}$ (bipy) by four times, due to the multi-phonon relaxation process arising from the harmonic vibration motion of $\mathrm{C}-\mathrm{H}$ bonds. In this section, our main material efforts have been focused on developing the new synthetic methodolgy of the inert, saturated $\mathrm{Er}^{3-}$ complexes and investigating important key parameters for near IR emission enhancement. The new synthetic methodolgy developed in our laboratory opens the development of a series of novel inert and stable Ln(III)cored nanophotonics systems with highly efficient lightharvesting effect and the investigation of efficient energy transfer pathways for the sensitization of $\mathrm{Ln}^{3-}$ jons by luminescent ligands in luminescent $\mathrm{Ln}^{3-}$ complexes. ${ }^{1.32}$

\section{Efficient Energy Transfer Pathways for the Sensitization of $\mathrm{Ln}^{3+}$ Ions by Luminescent Ligands in Luminescent $\mathrm{Ln}^{3+}$ Complexes}

Despite extensive research efforts, the energy transfer pathways in these complexes for the sensitization of the $\mathrm{Ln}^{3-}$ ions by the luminescent ligands are still not fully understood. Efficient energy transter pathways are very important in advanced photonics technology, particularly in the development of new and useful luminescent $\mathrm{Ln}^{3-}$ complexes with efficient lanthanide emission. For example, the development of integrated planar waveguide optical amplifiers is essential to the realization of superhigh speed communication systems. ${ }^{1.2}$ An optical amplification of $30 \mathrm{~dB}$ in a planar waveguide form is required.

Two possible energy transfer pathways for the sensitized emission in luminescent $\mathrm{Ln}^{3-}$ complexes were proposed, as shown in Scheme 4. It is well known that in general only the triplet state of the luminescent ligand is involved in photosensitization $(\mathrm{ET}(\mathrm{t}))$. The sensitization process of $\mathrm{Ln}^{3-}$

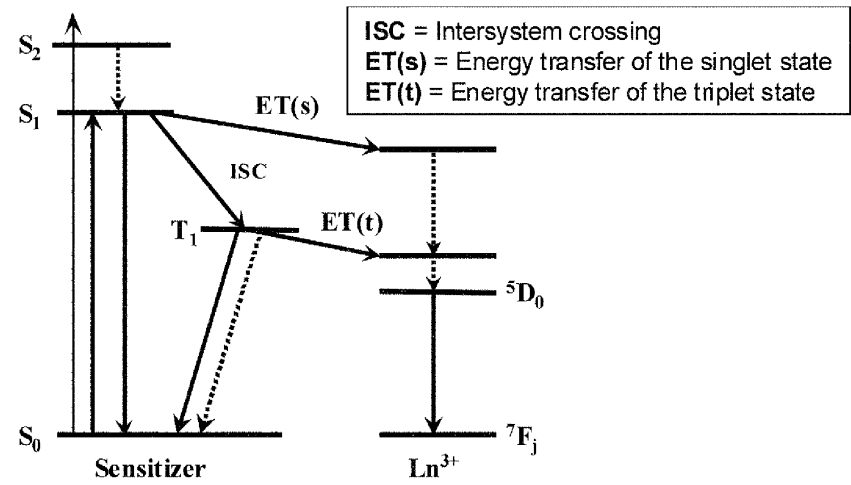

Scheme 4. Two possible energy transfer pathways.

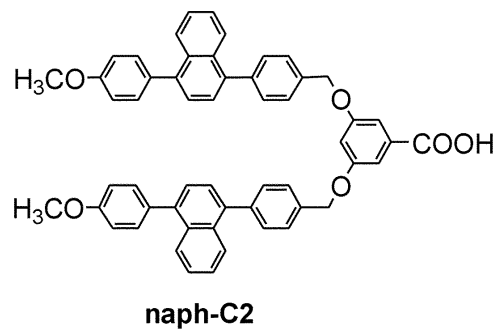

$$
\mathbf{R}-\mathrm{CO}_{2} \mathrm{H}+\mathrm{KH} \stackrel{\mathrm{Tpy} / \mathrm{Eu}\left(\mathrm{NO}_{3}\right)_{3} 5 \mathrm{H}_{2} \mathrm{O}}{\mathrm{THF}}
$$

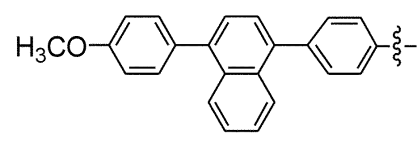

R:

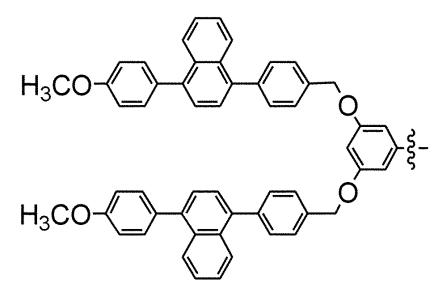

Scheme 5. Synthetic strategy tor the Eu(III)-cored complexes. 


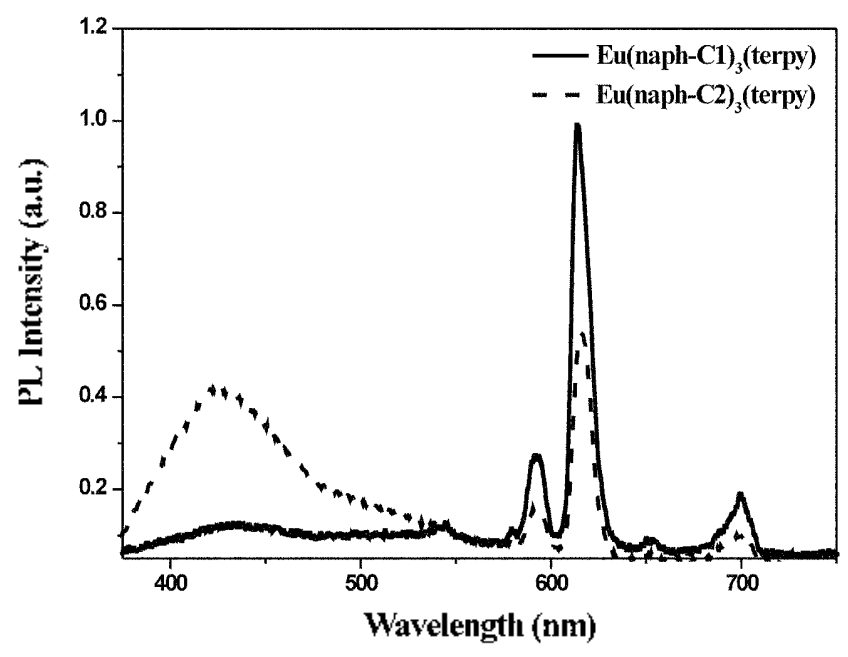

Figure 3. Emission spectra of the saturated complexes of Eu(naphC1)(terpy) $\left(\lambda_{\mathrm{x} x}=353 \mathrm{~nm}\right)$ and Eu(naph-C2) $\left(\right.$ terpy) $\left(\lambda_{\mathrm{cx}}=394 \mathrm{~nm}\right)$.

complex is strongly aftected by the subsequent intersystem crossing efficiency, and the energy transfer efficiency to I. $\mathrm{n}^{3-}$ ion in the excited triplet state, ${ }^{6.33}$ The possibility of energy transfer from the singlet state of the luminescent ligand $(\mathrm{ET}(\mathrm{s}))$ was thought to be very low, because this process is usually too slow to compete with other processes such as luminescent ligand fluorescence and intersystem crossing (ISC). Interestingly, however, several reports mentioned the energy transfer from the excited singlet state to $\mathrm{In}^{3-}$ ion. ${ }^{3+-36}$ van Veggel et al. ${ }^{3+}$ reported that the encrgy transfer in dansyl- and lissamine-functionalized $\mathrm{Nd}^{3-} \mathrm{com}-$ plexes oceured from the singlet state of the sensitizers to $\mathrm{Nd}^{3-}$ centers, but no sensitized $\mathrm{Yb}^{3-}$ or $\mathrm{Fr}^{3-}$ emission was observed. Balzani et $a t^{36}$ also observed the energy transfer between the singlet state of polylysin dendrimer and $\mathrm{Nd}^{3-}$ ions. Very recently, Wang et al. ${ }^{37}$ reported that the encrgy transfer in a dipyrazolyltriazine-functionalized $\mathrm{Eu}^{3-}$ complex occured from the singlet state of the sensitizers to $\mathrm{Eu}^{3-}$ centers.

In order to investigate the pathways for energy transfer from luminescent ligands to $\mathrm{Ln}^{3-}$ ions, we have systematically designed and developed naphthalene-based luminescent ligands as sensitizers, as shown in Scheme 5. These naphthalene-based luminescent derivatives were synthesized using the well-known Suzuki cross coupling reaction with moderate yield. ${ }^{21 \mathrm{t}}$ The UV-visible spectra of naph-C1 and naph- $\mathrm{C} 2$ have broad and intense band edges, which are due to $\pi-\pi^{*}$ clectronic transitions, tailing up to $374 \mathrm{~nm}$ with a maximum absorption wavelength of $312 \mathrm{~nm}$, and tailing up to $360 \mathrm{~nm}$ with a maximum absorption wavelength of 306 $\mathrm{nm}$, respectively. The photoexcitalion of naph-C1 and naphC2 with the light wavelengths of 344 and $350 \mathrm{~nm}$ results in PL spectra with strong emission bands at 429 and $400 \mathrm{~nm}$, respectively.

The Eu(III)-chelated complexes were obtained with a quantitative yield by a promising new synthetic method developed in our laboratory. The complexing of the naphthalene-based luminescent derivatives in Eu(IIJ)-cored luminescent complexes does not alter their UV absorption features. This indicates that the chelated ligands and $\mathrm{Ln}^{3-}$ do not perturb each other. In other words, the ground states of the $\mathrm{Lu}^{3-}$ ions are not influenced by the organic ligands, even in $\mathrm{Eu}^{3-}$ complexes. The emission spectra of the $\mathrm{Eu}^{3-}$ complexes Eu(naph-Cl);(terpy) and Eu(naph-C2);(terpy), obtained using different excitation wavelengths corresponding to the absorption maximum positions of the ligands, contain an intra $4 \int$ electronic transition from the first excited state $\left({ }^{5} \mathrm{~T}_{11}\right)$ to the ground state $\left({ }^{7} \mathrm{~F}_{2}\right)$ at $612 \mathrm{~nm}$ (sec Figure 3 ). $\mathrm{Cu}(\text { naph- } \mathrm{C} 1\}_{3}$ (terpy) has a much stronger PL intensity than $\mathrm{Eu}(\text { naph- }-\mathrm{C} 2)_{3}$ (terpy). This observation can be explained in terms of the more effective energy transfer between the ligands and the $\mathrm{Ln}^{3-}$ ions that occurs in Eu(naph-C1):(terpy) (ET(t)). Eu(naph-Cl) «(terpy) has a higher ISC efficiency for the conversion of the singlet state into the triplet state than $\mathrm{Cu}(\text { naph-C2 })_{3}($ terpy); this higher ISC efficiency is due to the heavy metal eflect that arises in Eu(naph-C1):(terpy), because naph-C1 is directly connected to the $\mathrm{L} \mathrm{n}^{3-}$ ions without a molecular spacer.

Eu(naph-C1) $)_{3}$ (terpy) and Eu(naph-C2) 3 (terpy) also have qualitatively different PI spectra. Fu(naph-C1)(terpy) produces one strong photoluminescence band with maximum wavelength around $612 \mathrm{~nm}$, while Eu(naph-C2):(terpy) produces two PL bands: a strong cmission band around 612 $\mathrm{nm}$ and an emission band of moderale intensity around 400 $\mathrm{nm}$. The latter band is assigned to fluorescence from the singlet state of the naphthalene-based luminescent ligand, because its absorption and emission spectra are mirror images of each other. This assignment is confirmed by the time-resolved transient decay. Further, the intensity of the cmission band at $400 \mathrm{~nm}$ was reduced, but the cmission band at $612 \mathrm{~nm}$ was simultaneously increased. The presence of an emission band near $400 \mathrm{~nm}$ indicales that no eflective energy transfer occurs between the naph-C2 ligand in $\mathrm{Cu}\left(\right.$ naph-C2) (terpy) and the $\mathrm{Ln}^{3-}$ ion. This might be because this indireet luminescent $\mathrm{Lrr}^{3-}$ complex contains a molecular spacer as a building block. In other words, the naphthalene-based luminescent derivatives are connected through building blocks to the $\mathrm{Ln}^{3-}$ ions. Thus, the effective formation of triplet states does not occur in complex $\mathrm{Cu}$ (naph-C2) 3 (terpy), because there is no heavy metal effect. However, Eu(naph-C2) \{ (terpy) exhibits nuch lower fluorescence inkensity around $400 \mathrm{~nm}$ than the naph-C2 ligand, presumably due to the singlet energy transfer from the luminescent ligand to the $\mathrm{Ln}^{3-}$ ion (ET(s)).

In summary, we have designed and developed novel luminescent $\mathrm{Ln}^{3-}$ complexes based on naphthalene derivalives for exploratory investigation of elficient energy transler pathway from lumineseent ligands to $\mathrm{L} \mathrm{n}^{3-}$ ions. $\mathrm{Ln}^{3-}$ ions were encapsulated with two types of the naphthalene-based Juminescent ligands. One of them can lead to the direct formation of lumineseent $\mathrm{L}^{3-}$ complexes without a molecular spacer and the other can render the indirect formation of luminescent $\mathrm{Ln}^{3-}$ complexes through a molecular spacer as a building block. With them, the involvement of the energy transfer of the singlet state of the luminescent ligand in 
Eu(III)-chelated complexes was investigated and demonstrated for the first time to the best our knowledge. This conclusion opens up the possibility of the development of a series of novel $\mathrm{Ln}(\mathrm{III})$-cored nanophotonics systems based on porphyrins, as well as of new antenna chromophores with highly efficient light harvesting dendritic arrays. ${ }^{1.32 .39}$

\section{Erbium(III)-Cored Conılexes Based on Metalloporphyrins Bearing Aryl-ether Dendron for Optical Amplification: Synthesis and Emission Enhancement}

Porphyrin derivatives were chosen for supramolecular ligands, since they are well-known as photon antenna for natural photosynthetic system. ${ }^{3 \$}$ Also, porphyrin ligands should have the following properties: First, they have enough donor atons and specitic isolation space for guest metal ions. It is possible to obtain the encapsulation of lanthanide ions and the isolation from light quenchable solvents such as water. Second, they have specific functional groups, in which they will be used to couple with antenua systems or light-harvesting systems. Third, the energy level of the triplet state of metalloporphyrins has the spectral overlap well with the ${ }^{4} \mathrm{~F}_{42}$ sublevel of $\mathrm{Er}^{3+}$ jons, which is another key paraneter to maintain the effective energy transfer process from metalloporphyrin ligands to $\mathrm{Er}^{3-}$ ions (see Figure 4), 30.37 .39

For the first of all, the porphyrin derivatives were synthesized according to previous procedures (see Scheme $6)^{.0 .41}$ Using them, we achieved successfully the synthesis of Er(III)-cored supramolecular complexes based on porplyyrins
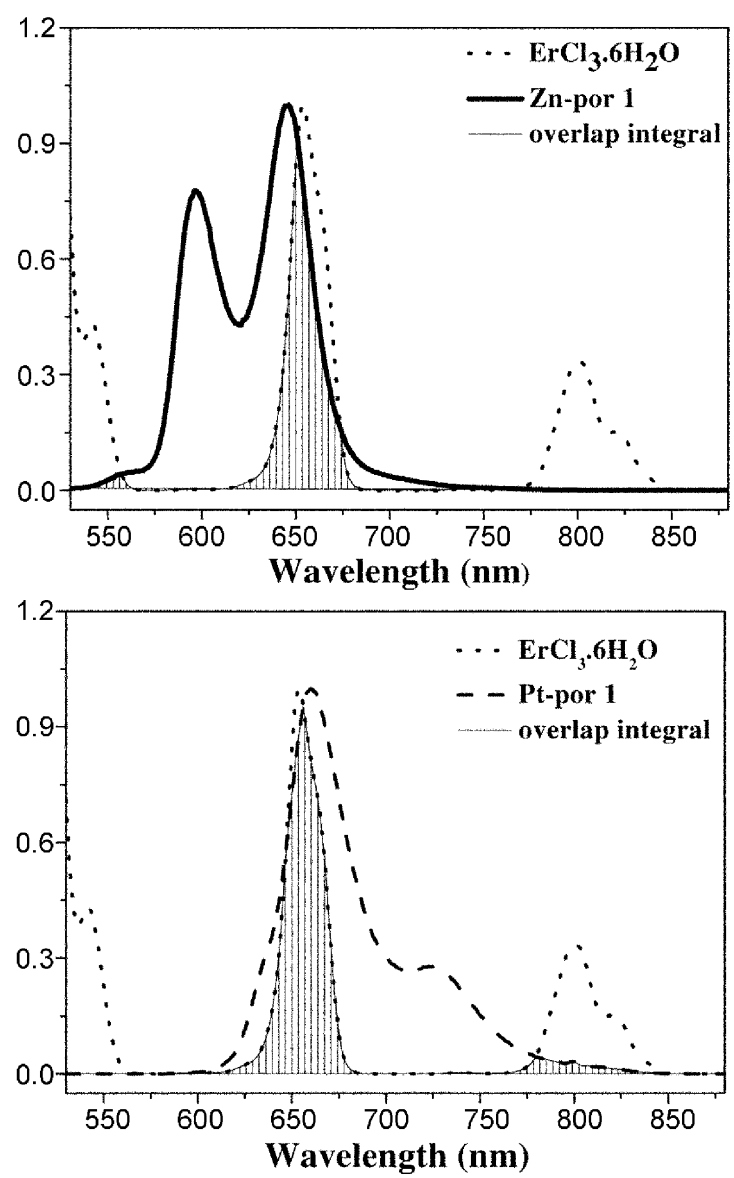

Figure 4. The spectral overlap integral between the emission band of porphyrin ligands and the absorption band of the erbium ion for the enfective energy transfer process from porphyrin ligands to the of erbium ions.

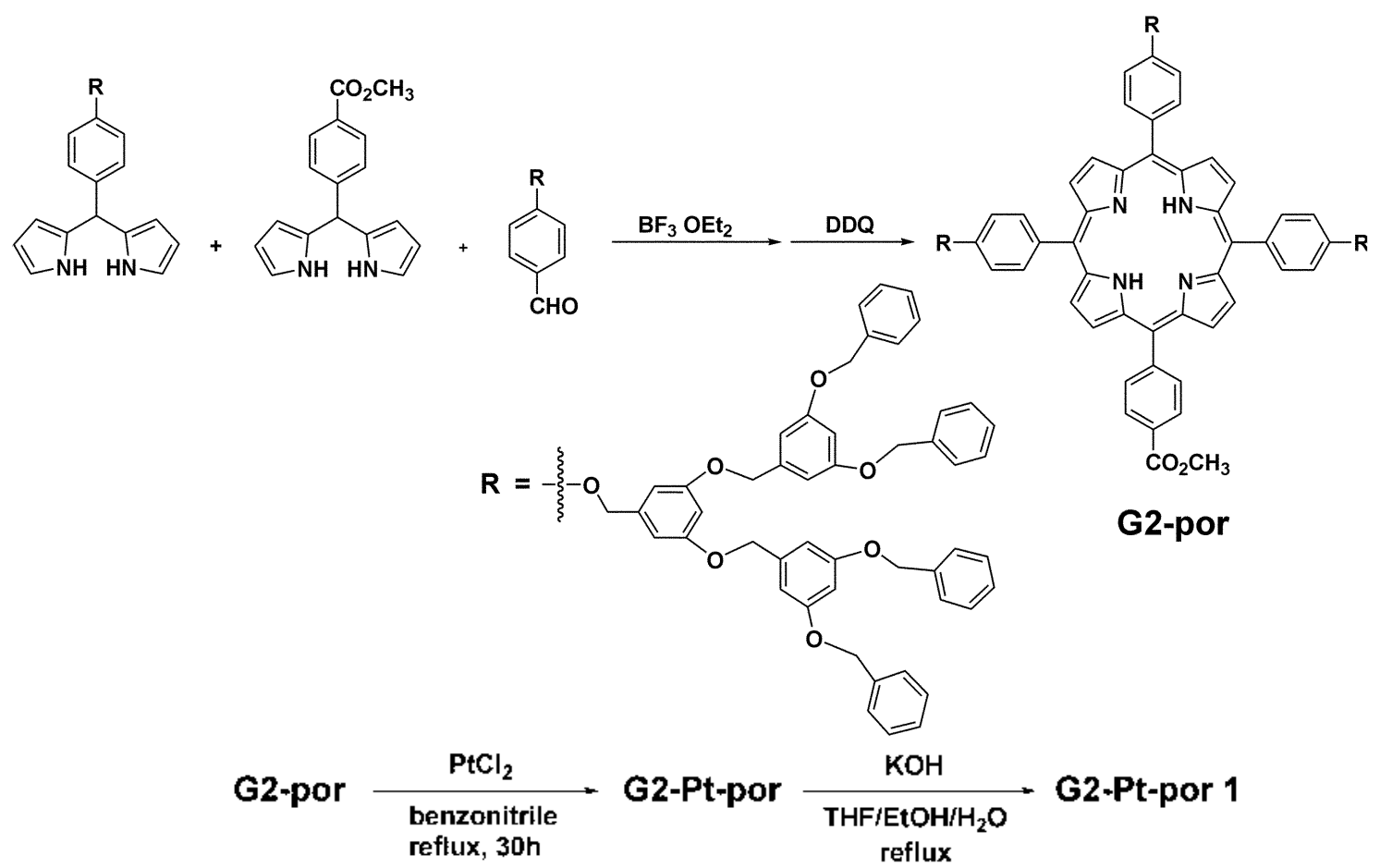

Scheme 6. Synthetic routes to G2-Por, G2-Pt-Por and G2-Pt-Por 1. 

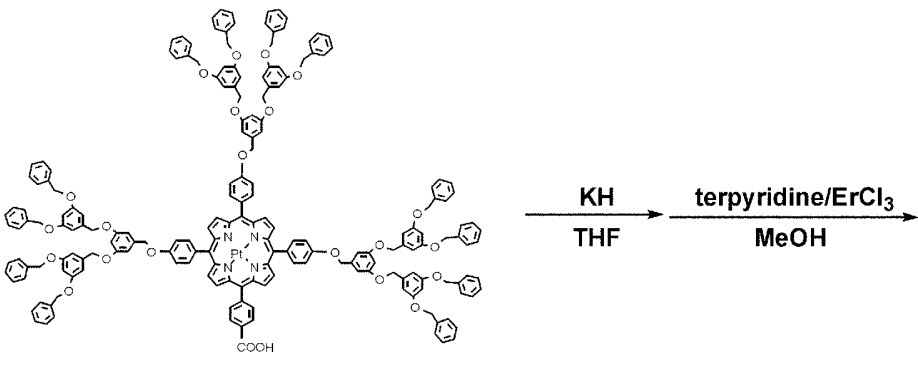

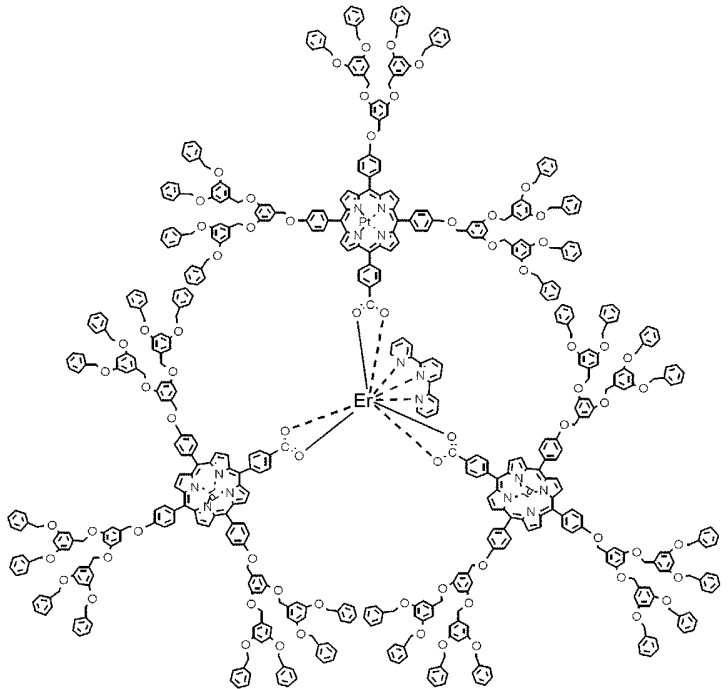

$\operatorname{Er}(\text { G2-Pt-por 1) })_{3}$ (terpy)
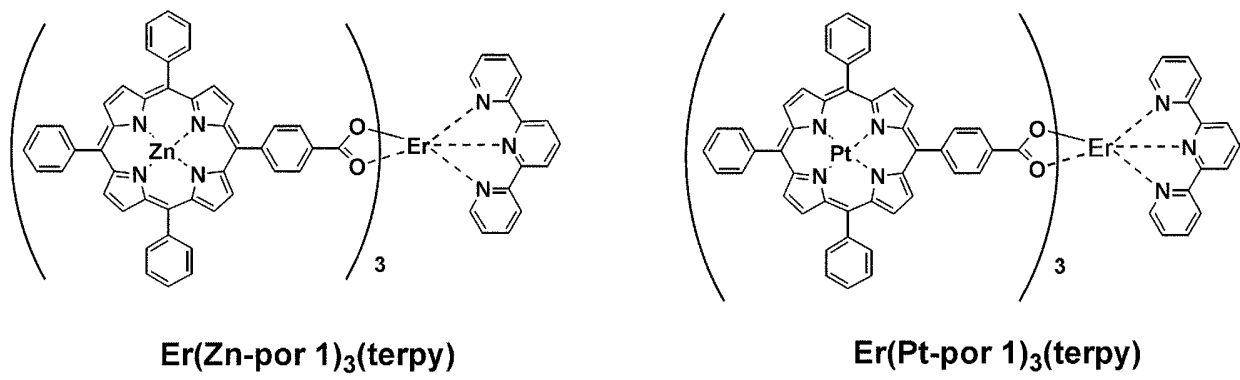

Scheme 7. Synthetic routes to G2-Pt-Por 1 and $\operatorname{Er}(\mathrm{G} 2-P t-p o r ~ 1)$; (terpy) as well as the chenical structures of $\operatorname{Er}\left(\mathrm{Znn}_{11} \text {-por } 1\right)_{\text {; }}$ (terpy) and Er(P1-por 1) sterpy).

using $\Gamma_{\mathrm{rCl}_{3}}$ in a novel synthetic method developed in our laboratory, yiclding more stable 9-coordinated Fr(III)-cored complexes (see Scheme 7), ${ }^{1.22 .42 .43}$ The chemical structures of Er(III)-cored complexes were identitied by FT-IR, NMR, Mass, absorption and emission spectroseopies. The FT-IR spectra of the Er(III)-cored complex exhibited the two characteristic bands of bidentate-like carboxylate around 1600 and $1410 \mathrm{~cm}$ ', indicating the formation of bidentate complex. ${ }^{21.44}$

Figure 5 shows the absorption and emission spectra of FBpor 1. 7n-por I, Pt-por 1 and G2-Pt-por 1. According to our previous report, the absorption of $\mathrm{Pt}(\mathrm{II})$-por 1 exhibits a blue shift by $20-40 \mathrm{~nm}$ to $\mathrm{Zn}$-por $\mathrm{l}$ and FB-por 1, due to a wide band gap of $\pi-\pi^{*}$ electronic transition arising from strong $\mathrm{d}$-p orbital interaction between unoccupied d-orbital in $\mathrm{Pt}^{2-}$ ions and p-orbital in porphyrins. ${ }^{45}$ G2-P1(II)-porphyrin shows a very intense Soret band at $406 \mathrm{~nm}$ and the relatively weak $Q$ bands at 511 and $540 \mathrm{~nm}$ as well as a moderate absorption band of $\mathrm{G} 2$ dendron at $276 \mathrm{~nm}$. All absorption bands of $\mathrm{G}_{2}$-Pl(II)-porphyrin are shifted to longer wavelenglh, compared with P(II)-porphyrin.

The PL spectrum of $\mathrm{Zn}$-por 1 shows a moderate band at $596 \mathrm{~nm}$ and a strong band at $646 \mathrm{~nm}$, while the PI, spectrum of Pt-por 1 shows a strong band at $660 \mathrm{~nm}$ and a moderate

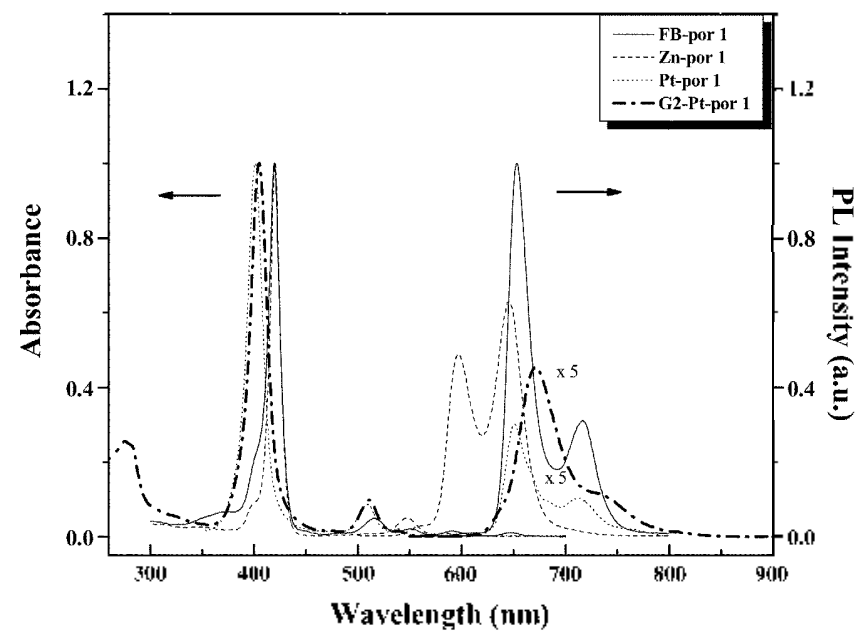

Figure 5. The UV-Vis, absorption and emission spectra of FB-por 1, Zn-por 1, Pt-por 1 and G2-Pt-por 1 in THF $\left(1 \times 10^{-5} \mathrm{M}\right)$.

band at $725 \mathrm{~nm}$. However, the PI. intensity of P1-por 1 is much lower than that of the $\mathrm{Zn}$-por 1 . It was previously explained by the fact that $\mathrm{P}(\mathrm{II})$-porphyrin derivative has the higher ISC efliciency for the conversion of a singlet state into a triplet state than that of $\mathrm{Zn}$ (II)-porphyrin derivative, 


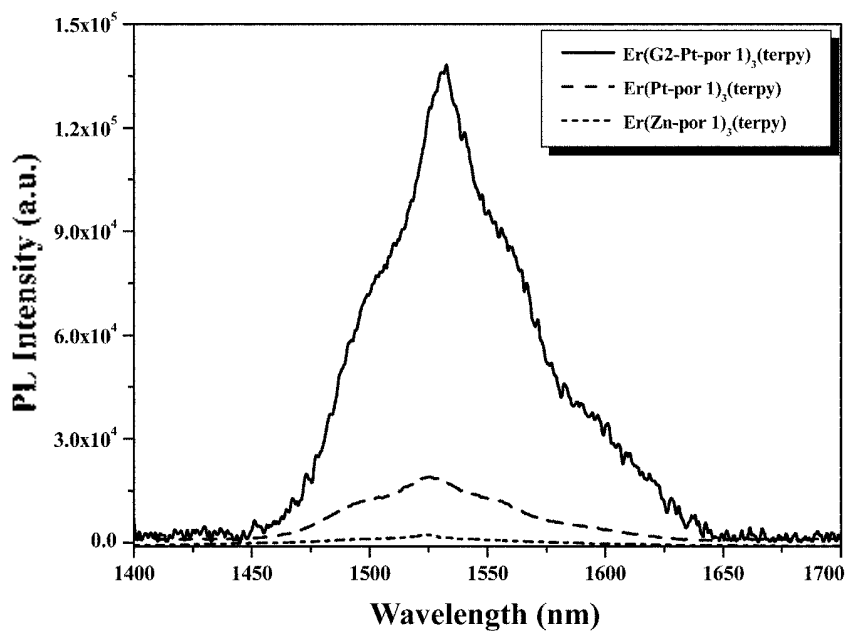

Figure 6. Near IR emission spectra of $\operatorname{Er}(\mathrm{Zn}-$ por 1):(terpy), Er(P1por 1$)_{3}$ (tespy), and $\mathrm{Er}(\mathrm{G} 2-\mathrm{Pt} \text {-por } 1)_{3}$ (terpy) ( $\hat{i}_{\mathrm{w}}=514 \mathrm{~nm}$ from $\mathrm{Ar}^{+}$ laser, solid state).

due to the heavy atom $P(I I)$ effect arising from the spinorbital coupling interaction. ${ }^{32 .+13}$ Upon a photocxcitation wavelength at the absorption maximum wavelength, the $\mathrm{PL}$ spectrun of G2-P1(II)-porphyrin shows a moderate band at $676 \mathrm{~nm}$ and a relatively weak band at $730 \mathrm{~nm}$, while the PI. spectrum of Pt-por I showed a strong band at $653 \mathrm{~nm}$ and a moderate band at $713 \mathrm{~nm}$. The similar result was observed with red shift for free $\mathrm{G}(\mathrm{n})$-aryl ether typed porphyrin derivatives. ${ }^{+7}$

The emission spectra of the saturated 9-coordinated Tre(II)-cored complexes based on $\mathrm{Zn}(\mathrm{II})$ - and $\mathrm{Pl}(\mathrm{II})$ porphyrin in a solid state were obtained from the excitation wavelengths of the absorption maximum positions of metalloporphyrins. They showed an intra $4 \uparrow$ shell electronic transition from its lirst excited state $\left({ }^{\dagger} I_{13: 2}\right)$ to the ground state $\left({ }^{4} I_{152}\right)$, taking place al $1.53 \mathrm{~cm}$ (see Figure 6). Surprisingly, the Zn(II)-porphyrinate complex shows two strong PL bands at 596 and $646 \mathrm{~nm}$, bul, no near IR cmission band. It indicates that $\mathrm{Zn}(\mathrm{II})$-porphyrin could not act as a sensitizer in the $\mathrm{Zn}$ (II)-porphyrinate complex to maintain the energy transfer between the $\mathrm{Zn}(\mathrm{II})$-porphyrin ligand and $\mathrm{Ln}^{3-}$ ion, even though the spectral overlap integral of the $\mathrm{Zn}$ (II)-porphyrin ligand is similar to that of the $\mathrm{P}(\mathrm{II})$ porphyrin ligand (see Figure 4). However, the PI(II)porphyrinate complex exhibits only the near IR emission band without the visible PL band of Pt-por 1 . It is noteworthy that $\mathrm{Pl}(\mathrm{II})$-porphyrin derivative has the higher ISC efficiency for the conversion of a singlet state into a triplet state than that of $\mathrm{Zn}$ (II)-porphyrin derivative, due to the heavy atom Pt(II) eflect arising from the spin-orbital coupling interaction. It suggests that the emission bands of the Er(III)-cored complex based on Pt(II)-porphyrin in the visible region may be originated from the triplet state. It is apparently different from the origin of $\mathrm{Zn}$ (II)-porphyrin emission bands. Therefore, we can guess that the effective energy transfer from the ligand to I. ${ }^{3-}$ ion takes place through the triplet state.

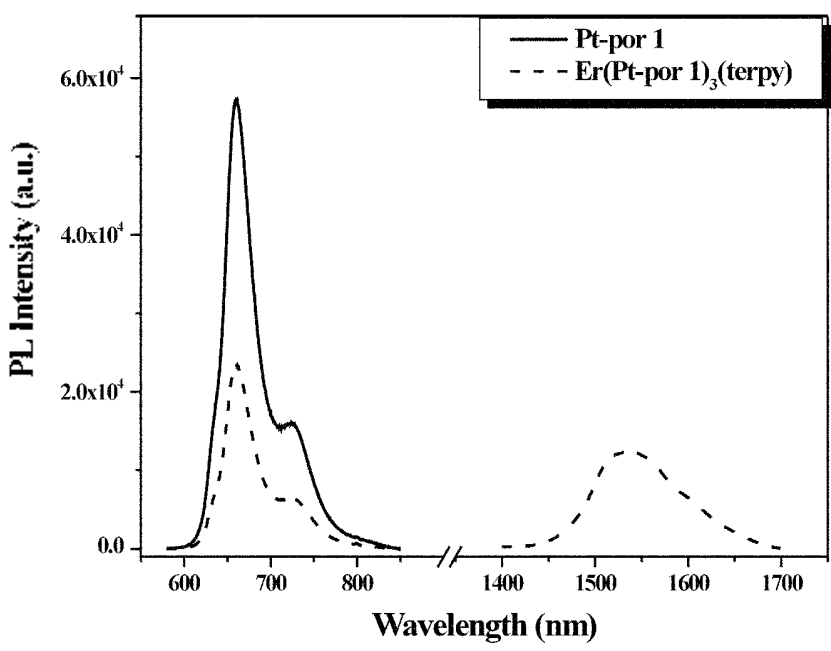

Figure 7. The photoluminescence spectra of Pt-posphyrin- $\mathrm{COOH}$ (Pt-por 1) and $\operatorname{Er}\left(\mathrm{J}^{2 t}\right.$-por 1):(terpy) at room temperature in deoxygenated THF solutions $\left(1 \times 10^{-5} \mathrm{M}\right)$ upon a photoexcitation wavelength of $405 \mathrm{~nm}$.

The direc evidenee of the formation of the triplet state as an energy transfer state was confirmed by measuring the phosphorescence spectra of the Pt(II)-porphyrin ligand and its Fr(III)-cored complex (see Figure 7) and the decay time for the Er(III)-cored complex in deoxygenated THF solutions at room temperature. The ligand exhibits a strong phosphorescence maximum band around $660 \mathrm{~nm}$ and a moderate phosphoreseence maximum band around $725 \mathrm{~nm}$. However, the complex shows the near IR emission band at $1.53 \mathrm{\mu m}$, but, the intensity of the phosphoreseence bands was strongly reduced. The decay lime of the phosphorescence band was found to be $30 \mu$ is for the $\operatorname{Er}(\mathrm{III})$-cored complex. In addition, sine the triplet state was seriously quenched by oxygen, we have investigaled the oxygen effect for the sensitized near IR luminescence intensity in the Lr(III)-cored Pt(II)-porphyrinate complex (see Figure 8).

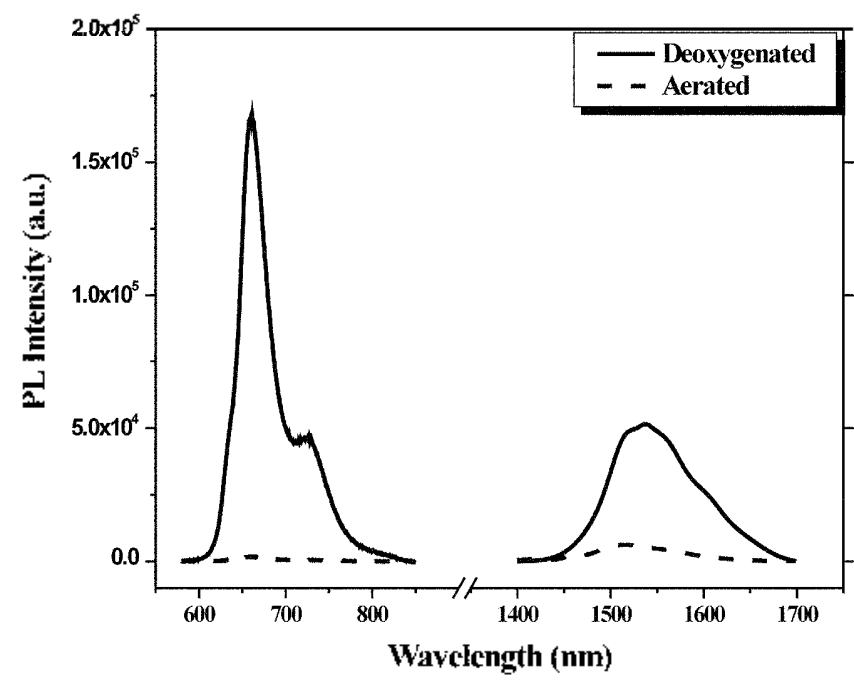

Figure 8. The photoluminescence spectra of (P1-por l) 3 (terpy) at room temperature in a deoxygenated and an acsated THF solutions $\left(1 \times 10^{-5} \mathrm{M}\right)$ upon a photoexcitation wavelength of $405 \mathrm{~nm}$. 
The emission intensity in the acrated THF solution is seriously quenched not only in the visible region but also in the near IR region. It indicates that the energy transfer takes place through the triplet state of the $\mathrm{P}$ (II (II)-porphyrin ligands. Also, the effect of oxygen on the sensitized luminescence intensity gives an estimation of the energy transfer rate with the order of $10^{7}-10^{8} \mathrm{sec} 16$

Furthermore, in order to enhance the photophysical properties of novel supramolecular systems, we have incorporated a $\mathrm{G}_{2}$-aryl ether-functionalized dendron into the Er(IIJ)-cored Pt(II)-porphyrinate complex (see Scheme $7)^{4 \times .49}$ It is well-known that the excited state of the $\mathrm{Ln}^{3-}$ ions is seriously quenched by interactions with close $\left[n^{3-}\right.$ ions. ${ }^{50}$ It limits Er(IJI)-doped concentration on silica optic fiber up to $100-1000 \mathrm{ppm}$. With this reason, it is impossible to obtain the optical amplification gain of higher than $30 \mathrm{~dB}$ with $\mathrm{Er}^{3-}$-doped silica optical fibers for developing integrated

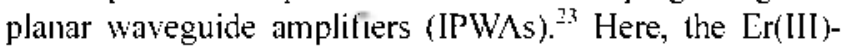
cored dendrimer complex based on $\mathrm{P}(\mathrm{II})$-porphyrin was designed to protect the interaction between the $\mathrm{Ln}^{\mathrm{i}}$ ins and to isolate the $\mathrm{Ln}^{3-}$ ion from the quenching molecules (solvents and $\mathrm{H}_{2} \mathrm{O}$ ).

With an excitation al the absorption maximum wavelength of the Pt(II)-porphyrin in a solid state, the Er(III)-cored dendrimer complex with P(II)-porphyrin bearing a $\mathrm{G}$-aryl ether dendron has the higher PL intensity than the saturated 9-coordinated Er(JII)-cored P(II)-porphyrinate complex by 7 times (see Figure 6). It might be due to the fact that aryl cher-typed dendritic porphyrin renders the eflicient siteisolation effect enough to prevent the intermolecular interaction between $\mathrm{Er}^{3-}$ ions, which limits the near IR intensity. $A \mathrm{Iso}$, we have measured the lumineseence and the decay time of Er(III)-cored dendrimer complex with P(II)porphyrin bearing a G2-aryl ether dendron in deoxygenated THF solution. The similar results were obtained to the Er(IIJ)-cored Pt(II)-porphyrinate complex (see Figure 8), since the emission intensity in both the visible and near IR regions, in deoxygenated condition, is highly increased. "2ih,
It indicates that the (.2-aryl ether dendron in the एr. (III)cored dendrimer complex prevents the Er(III)-cored dendrimer complex from penetrating the oxygen into the cored $\mathrm{Er}^{3-}$ ions. Thus, it reduces the effect of oxygen on the sensitized luminescence intensity. ${ }^{6} \mathrm{Also}$, the decay time of the phosphorescence band in the P( $(\mathrm{Il})$-porphyrin was measured to be $40 \mu / \mathrm{s}$ for the Fr(II)-cored dendrimer complex, indicating that the energy transfer takes place through the triplet state of the P(II)-porphyrin ligands like the Er(III)cored complex based on P1(II)-porphyrin. Therefore, PI(II)porphyrin derivatives bearing aryl ether-typed dendrons are good candidates for encapsulating supramolecules as well as the photon antenuas to Tr(III)-cored supramolecular complexes.

In progress, additionally, to efficiently introduce the lightharvesting effect into our [r. (IIJ)-cored supramolecular systems for optimizing and maximizing their optophysical properties, we have designed and synthesized a series of [r(III)-cored dendrimer complexes bearing new aryl ethertyped dendrons with energy gradient. ${ }^{1.39 .50 .51}$ The synthetic strategy and the energy transfer pathway of novel lanthanide-cored supramolecular systems with highly clficient light-harvesting dendritic arrays are described in Scheme 8. Our supramolecular systems have hoth lanthanide-cored supramolecular complexes and light-harvesting dendritic photon antenna with such proper energy gradient. In our supramolecular systems, many exterior chromophores efliciently absorb and transfer the light through the interior chromophores to the supramolecular ligands via energy transfer process, so-called the light-harvesting effect, leading to the formation of the singlet state of the supramolecular ligands. And then, the singlet state of the supramolecular ligands is converted into their triplet state by ISC process. The triplet state of the supramolecular ligands must be tailored to maintain the upper energy level than the lower excited energy level ( $\left.\mathrm{Cr}^{3-},{ }^{4} \mathrm{I}_{13 \cdot 2}\right)$ of the lanthanide ions, and then transited to the lower excited energy level ( $\mathrm{T}^{3-}{ }^{3-},{ }^{4} \mathrm{I}_{132}$ ) of the lanthanide ions through the vibrational relaxation
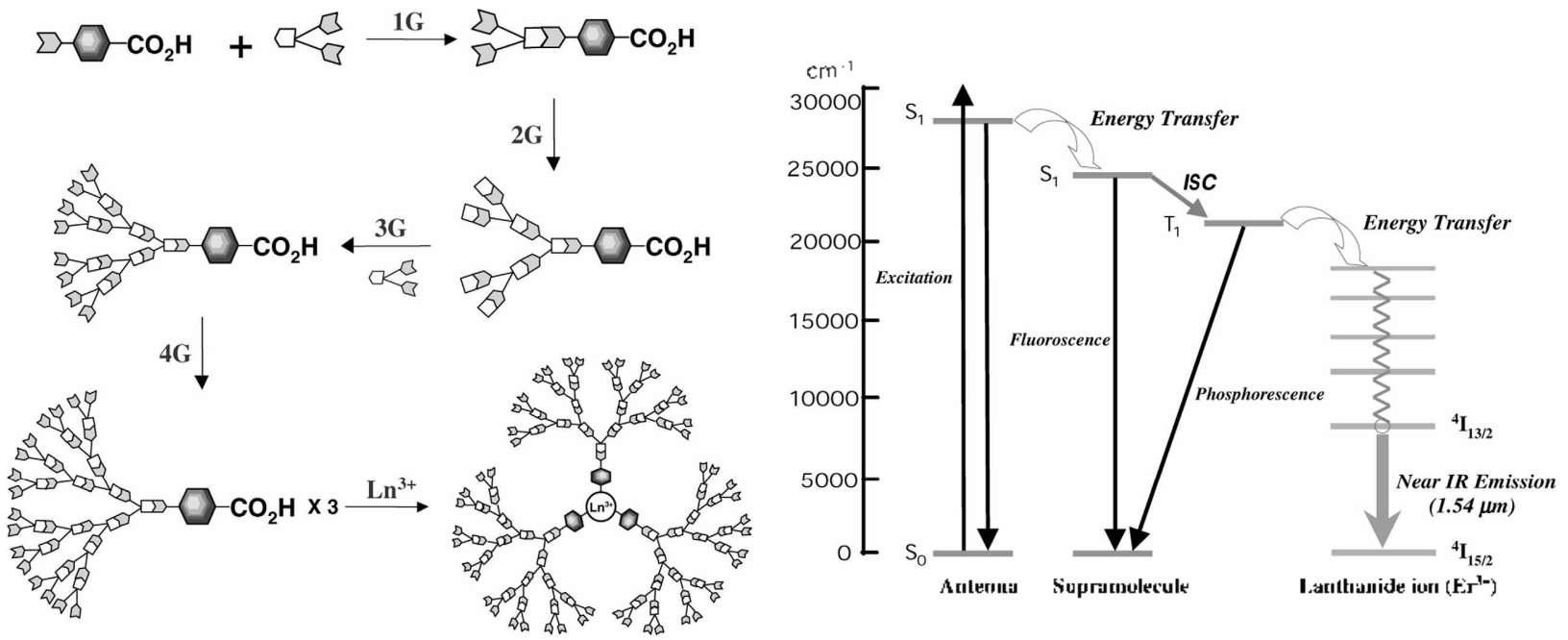

Scheme 8. Synthetic strategy and energy transfer pathway of novel lanthanide-cored supramolecular systens with highly efficient lightharvesting dendritic arrays. 
process. Eventually, it falls back to the ground state $\left(\mathrm{Er}^{3+}\right.$. ${ }^{4} \mathrm{I}_{\left.1 s_{2}\right)}$ ) of the lanthanide ions, emitting the stimulated emission. It is very important to note that the accumulating photon energy from the triplet state of the supramolecular ligands can excite the lanthanide ions as much as possible. thus maximizing the optical amplification gain. Also, the optophysical properties of the lanthanide-encapsulated supramolecular systems are optimized and maximized during artificially light gathering and transferring by way of using the light-harvesting principle of naturally existing photo-synthetic antenna.

\section{Summary and Outlook}

New synthetic methodology of the saturated and unsaturated $\operatorname{Er}(\mathrm{III})$-chelated prototype complexes based on benzoate and pentafluorobenzoate ligands was successfully developed through the ligand-exchange reaction. The saturated 8-coordinated $\mathrm{Er}^{3-}$ complexes exhibit stronger near-IR emission than those of the unsaturated 6-coordinated $\mathrm{Er}^{3+}$ complexes. Also, the saturated $\mathrm{Er}$ (III)-chelated complex with $\mathrm{C}-\mathrm{F}$ bonds shows much stronger near IR emission than that of the saturated $\operatorname{Er}(\mathrm{III}$-chelated complex with $\mathrm{C}$-H bonds. It is attributed to the influence of C-F bonds on near IR emission. We also have designed and developed novel luminescent $\mathrm{Eu}^{3-}$ complexes based on naphthalene derivatives in order to investigate and understand efficient energy transfer pathways from luminescent ligands to $\mathrm{Ln}^{3-}$ ions in luminescent $\mathrm{Ln}^{3-}$ complexes. The direct luminescent $\mathrm{Ln}^{3+}$ complex has much higher PL efficiency than the indirect luminescent $\mathrm{Ln}^{3+}$ complex, due to a higher ISC efficiency in a direct complex. In the indirect luminescent $\mathrm{Ln}^{3+}$ complex. the involvement of the energy transfer of the singlet state of the luminescent ligand was investigated and demonstrated for the first time to the best our knowledge. Furthermore, we have developed novel inert and stable, direct $\operatorname{Er}(\mathrm{III})$-cored supramolecular complexes based on metalloporphyrins. $\mathrm{Er}^{3+}$ ions were encapsulated by the metalloporphyrins ligands. such as $\mathrm{Zn}(\mathrm{II})$ - and $\mathrm{Pt}(\mathrm{II})$-porphyrins. The $\mathrm{Er}(\mathrm{III})$-cored supramolecular complex based on Pt(II)-porphyrin has the much higher PL efficiency than Er(III)-cored supramolecular complex based on Zn(II)-porphyrin, due to the higher ISC efficiency for the conversion of a singlet state into a triplet state than that of $\mathrm{Zn}(\mathrm{II}$-porphyrin derivative. The triplet state of Pt(II)-porphyrin in $\mathrm{Er}$ (III) complex based on $\mathrm{Pt}(\mathrm{II})$-porphyrin was also detected with its lifetime of $30 \mathrm{~ms}$. Also, the Er(III)-cored dendrimer complex with a G2-aryl ether dendron has the higher PL intensity than the saturated 9-coordinated complex by 7 times, due to the efficient siteisolation effect. This investigation opens the development of a series of novel Ln(III)-cored supramolecular systems based on metalloporphyrins and new antenna chromophores with highly efficient light-harvesting effect.

Such efforts are just in the early stage and not only the basic concept not established, but also the structure-property relationship is not yet clearly understood. Therefore, the dependences of $\mathrm{Ln}^{3-}$ ion and ligand structure on ampli- fication principles (such as the optical amplification lifetime, excited state dynamics, etc.) need to be systematically established. Based on the relationship established, the design and synthesis of the highly efficient light-harvesting integrated supramolecular systems based on Ln(III)-cored dendritic or supramolecular complexes using molecular engineering approach need to be investigated to optimize opto-physical properties during artificially light gathering and transferring by way of using principles of natural photosynthetic antenna. In addition, the establishment of basic principles of amplification, including the dependence of $\mathrm{Ln}^{3+}$ complexes and ligand structure on excited state dynamics and lifetimes, as well as the elucidation of basic energy transformation and transfer mechanisms, will be investigated with regard to understand the structure-property relationships.

Based on the structure-property relationships to be determined, ultrahighly efficient light-harvesting supramolecular structures will be optimized and their application as the future optical amplification devices will be examined. Utilizing our developed materials, we will have the leverage to lead the world in tomorrow's communication technology and the technological impact will be similar to the integrated circuit development in semiconductor industries. This will not only be considered to be the material revolution in the heart of exploratory materials in optical information and communication, but also will open up many new areas of applications of polymeric materials for use in ultrahigh speed communication and information systems for the future generation.

Acknowledgement. This research work was financially supported from the Korea Ministry of Science and Technology through Creative Research Initiative Project as well as National Research Laboratory Program at Hannam University.

\section{References}

1. Kim, H. K.; Rol, S. G; Hong, K.-S.; Ka, J.-W.; Baek, N. S.; Oh, J. B.: Nall, M. K.: Cha, Y. H.: Ko, J. Afacromol Res. 2003, /(3), 133 and see references cited therein.

2. Roh, S.-G; Baek, N. S.; Ka, J.-W.; Joo, D. L.; Lee, J. C.; Nah, M. K. Ma, S. M.; Oh, J. B.; Paik, K. L.; Cha,Y. H. , Jo, J. H.; Kim, H. K. Polyner Sci. \& Technol.(SPK) 2002, 13(6), 783.

3. Oude Wolbers, M. P; van Veggel, F. C. J. M.; Peters, G A.; van Beelen, E. S. E.; Hotstraat, J. W.; Guerts, F. A. J.; Reinhoudt, D. N. Chen. Eur J. 1998, 4, 772 .

4. Slooff, L. H.; Polman, A.; Oude Wolbers, M. P.; van Veggel, F. C. J. M.; Reinhoudt, D. N.; Hofstraat, J. W. J. Appl. Phns: 1998, 83, 497.

5. Klink, S. 1.; Hebbink, G A.; Grave, L.; van Veggel, F. C. J. M.; Reinhoudt, D. N.; Slooff, L. H. J. Appl. Phis 1999, 86, 1181.

6. Klink, S. I.; Grave, L.; Reinhoudt, D. N.; van Veggel, F. C. J. M.; Werts, M. H. V.; Guerts, F. A. J.; Hofstraat, J. W. J. Phıs Chem. A $2000,104,5457$.

7. Slooff, L. H.; Polman, A.; Klink, S. I.; Hebbink, G. A.; Grave, L; van Veggel, F. C. J. M.; Reinhoudt, D. N.; Hofstraat, J. W. Opt. Aater: 2000, 14, 101.

8. Slooff, L. H.; Polman, A.; Cacialli, F.; Friend, R. H.; Hebbink, G. 
A.; van Veggel, F. C. J. M.; Reinhoudt, D. N. Appl. Phns. Len. 2001, 78, 2122.

9. Werts, M. H. V.; Hofstraat, J. W; Geurts, F. A. J.; Verhoeven, J. W. Chem. Phis. Lett. 1997, 276, 196.

10. Gillin, W. P; Cury, R. J. Appl. Phs. Lett. 1999, 74, 798.

11. Curry, R. J.; Gillin, W. P. Appl. Phs. Lett. $1999,75,1380$.

12. Curry, R. J.; Gillin, W. P. Sin. Mef. 2000, $M /, 35$.

13. Kawamura, Y.; Wada, Y.; Hasegawa, Y; Iwamuro, M.; Kitamura, T.; Yanagita, S. Appl. Phis. Leff. 1999, 74, 3245.

14. Kawamura, Y.; Wada, Y.; Iwamuro, M.; Kitamura, T.; Yanagita, S. Chem. Lett. 2000, 2943 ), 280.

15. Hasegawa, Y.; Olkubo, T.; Sogabe, K.; Kawamura, Y.; Wada, Y.; Nakashima, N.; Yanagita, S. Angen. Chent. Int. Ed. Engl. 2000, 39,357 .

16. Harrison, B. S.; Foley, T. J.; Bouguettaya, M.; Boncella, I. M.; Reynolds, J. R.; Schanze, K. S. S.; Shim, J.; Holloway, P. H.; Padmanaban, G; Ramakrislunan, S. Appl. Phis. Lett. 2001, 79 , 3770 .

17. (a) Kang, T.-S; Harrison, B. S.; Foley, T. I; Knefely, A. S.; Boncella, T. M.; Reynolds, J. R.; Schanze, K. S. Ach: Moter: 2003, 15, 1093. (b) Harrison, B. S.; Foley, T. I.; Knefely, A. S.; Cunningham, G B.; Kang, T.-S.; Bouguettaya, M.; Boncella, J. M.; Reynolds, J. R.; Schanze, K. S. Chem. Mater: 2004, 16, 2938.

18. Destri, S.; Porzio, W.; Meinardi, F.; Tubino, R.; Salemo, G. Macrontolecules 2003, 36, 273 .

19. Kawa, M.; Fréchet, J. M. I. Chent. Mater 1998, 10, 286.

20. Paik, K. L; Kim, H. K. Mol. Chys. Liq. Cryst. 2001, 370, 185.

21. (a) Baek, N. S.; Nah, M. K.; Kim, Y. H.; Roh, S.G.; Kim, H. K. Bull. Korean Chem. Soc. 2004, 25, 443. (b) Roh, S.G; Baek, N. S.; Hong, K.-S.; Kim, H. K. Bull. Korean Chem. Soc. 2004, $25,343$.

22. (a) Roh, S.-G; Oh, I. B; Nah, M. K.; Baek, N. S.; Lee, Y; Kim, H. K. Bull. Korean Chent. Soc. 2004, 25, 1503. (b) Roh, S.-G; Nah, M. K.; Oh, J. B.; Baek, N. S.; Kim, H. K. Polyhedron 2005, 24,137

23. Desurvire, E. Enbrum-doped Fiber Amplifiers: Principles and Applications; John Wiley \& Sons, lnc: New York, 1994.

24. Macfarlane, R. M.; Shelby, R. M. Spectroscopl of Solids Confaining Rare Earth Ions; Kaplyanskii, A. A., Macfarlane, R. M., Eds.; North-Holland: Amsterdam, 1987; pp 51-184.

25. Judd, B. R. Phis. Rev: $1962,127,750$.

26. Ofelt, G. S. J. Chem. Phis. 1962, 37, 511 .

27. Wyboume, B. G Spectroscopic Properties of Rare Earths; Interscience: New York, 1965.

28. Axe, Jr., J. D. J. Chem. Phrs. 1963, 39, 1154

29. Barasch, G. E.; Dieke, G H. J. Chen. Phns. 1965, 43, 988.

30. (a) Riseberg, L. A.; Moos, H. W. Phis. Rev Lett. 1967, 19, 1423; (b) Risebery, L. A.; Moos, H. W. Phis. Rev: 1968, 174, 429

31. (a) Dieke, G. H.; Crosswhite, H. M. Appl. Opt. 1963, 2, 681. (b) Carnall, W. T.; Crosswhite, H.; Crosswhite, H. M. Argonne National Laborafory Report; No. ANL-78-XX-95, 1977.

32. (a) Oh, I. B.; Baik, K. L.; Ka, J. W.; Roh, S. G.; Nah, M. K.; Kim, H. K. MRS Simp. Proc. Ser: 2003, 771,195 . (b) Oh, J. B.; Kim, Y.
H.; Nah, M. K.; Kim, H. K. J. Liminescence (Special issue on dendimersi 2005, in press.

33. (a) Oude Wolbers, M. P.; van Veggel, F. C. J. M.; Snellink-Ruel, B. H. M.; Hof'strat, J. W. Geurts, F. A. J.; Reinlhoudt, D. N. $J$. Am. Chem. Soc 1997, 119, 138. (b) Kleinerman, M. $J$. Chem Phvs. 1969, 51, 2370. (c) Sabbatini, N.; Guardigli, M.; Manet, I. Adi: Photochen. 1997, 43, 549. (d) Rudzinski, C. M.; Engebretson, D. S.; Hartmann, W. K.; Nocera, D. G. J. Phss. Chent A 1998, 102, 7442

34. Hebbink, G A.; Klink, S. I.; Grave, L.; Alink, P. G. B. O.; van Veggel, F. C. J. M. ChemPhisChem. 2002, 3, 1014.

35. Thome, J. R. G.; Rey, J. M.; Denning, R. G.; Watkins, S. E.; Etchells, M.; Green, M.; Christou, V. J. Phis. Chem. A 2002, $106(16), 4014$.

36. (a) Vicinelli, V; Ceroni, P.; Maestri, M.; Balzani, V.; Gorka, M.; vogtle, F. J. Am. Chem. Soc. 2002, 124(22), 6461. (b) You, B.; Kim, H. J.; Park, N. G; Kim, Y. S. Bull. Korean Chem. Soc. 2001, 22. 1005.

37. Yang, C.; Fu, L. M.; Wang, Y; Zhang, I. P.; Wong, W. T.; Ai, X. C.; Qiao, J. P; Zou, B. S.; Gui, L. L. Angen: Chen. In. Ed. 2004, 43,5010 .

38. McDenmott, G.; Prince, S. M.; Freer, A. A.; HawethonthwaiteLawless, A. M. Z.; Cogdell, R. J.; Isaacs, N. W. Nante 1995, 374, 517.

39. Kim, H. K.; Roh, S. G.; Ka, J. W; Kim, Y. H.; Nah, M. K.; Oh, J. B.; Baek, N. S. Korean Patent and International PCT Patent registered (October 28, 2004; PCT Publication No. WO 2004/ $092105 \mathrm{Al})$.

40. Ka, J.-W.; Kim, H. K. Tetrahedron Letters 2004, 45, 4519

41. (a) Lindsey, J. S.; Prathapan, S.; Jolunson, T. E.; Wagner, R. W. Tetwhedron 1994, 50, 8941. (b) Littler, B. J.; Ciringh, Y.; Lindsey, I. S. J. Org. Chent. 1999, 64, 2864.

42. Kawa, M; Fréchet, J. M. J. Thin Solid Films 1998, 331, 259.

43. Oh, J. B.: Paik, K. L.: Ká, J.W.: Roh, S.G.; Nah, M. K.; Kim, H. K. Hat. Sci. Eng. C 2004, 24, 257.

44. Nakamoto, $\mathrm{K}$. Infrared and Raman Spectra of Inorganic and Coordination Conpounds. Part B: Application in Coondination, Organontetallic, and Bioinorganic Chentist 1 , sth ed; John Wiley \& Sons: New York, 1997; pp 59-62.

45. Anderson, H. L. Chem. Comm. 1999, 23, 2323.

46. Scheer, H.; Schneider, S. Photostnthetic Light-Harvesting Svstems; W. de Gruyter: Berlin, 1988.

47. Jiang, D.-L; Aida, T. J. An. Chen. Soc 1998, 120, 10895.

48. Vögtle, F.; Gorka, M.; Vicinelli, V.; Ceroni, P.; Maestri, M.; Balzani, V. ChemPhschem. 2001, 2, 769.

49. Adronov, A.; Gilat, S. L.; Fréchet, J. M. J.; Ohta, K.; Neuwahl, F. V. R.; Fleming, G. R. J. Am. Chem. Soc. 2000, 122, 1775.

50. Kim, H. K.; Baek, N. S.; Oh, J. B.; Roh, S.-G.; Kim, Y. H.; Nah, M. K.; Hong, K.-S.; Song, B. I.; Zhou, G. J. Nonlinear Optical Phisics \& Materials 2005, in press.

51. Baek, N. S.; Kim, Y. H.; Roh, S.-G.; Kim, H. K. Advanced Haterials, submitted (2005). 